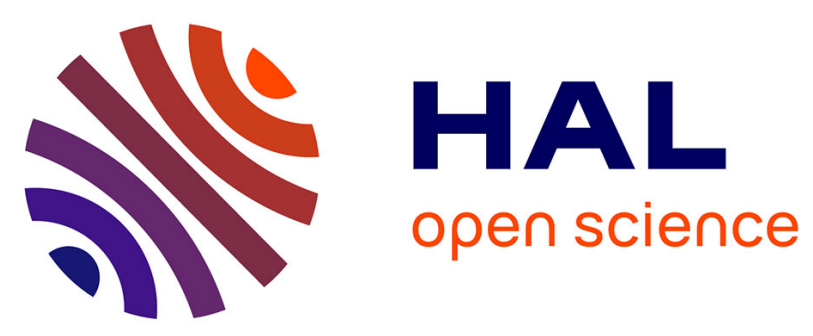

\title{
Ecological network analysis metrics: The need for an entire ecosystem approach in management and policy
}

Brian Fath, Harald Asmus, Ragnhild Asmus, Dan Baird, Stuart Borrett, Victor de Jonge, Alessandro Ludovisi, Nathalie Niquil, Ursula Scharler, Ulrike Schückel, et al.

\section{To cite this version:}

Brian Fath, Harald Asmus, Ragnhild Asmus, Dan Baird, Stuart Borrett, et al.. Ecological network analysis metrics: The need for an entire ecosystem approach in management and policy. Ocean and Coastal Management, 2019, 174, pp.1-14. 10.1016/j.ocecoaman.2019.03.007 . hal-02152462

\section{HAL Id: hal-02152462 \\ https://hal.science/hal-02152462}

Submitted on 16 Dec 2020

HAL is a multi-disciplinary open access archive for the deposit and dissemination of scientific research documents, whether they are published or not. The documents may come from teaching and research institutions in France or abroad, or from public or private research centers.
L'archive ouverte pluridisciplinaire HAL, est destinée au dépôt et à la diffusion de documents scientifiques de niveau recherche, publiés ou non, émanant des établissements d'enseignement et de recherche français ou étrangers, des laboratoires publics ou privés. 


\title{
Ecological network analysis metrics: The need for an entire ecosystem approach in management and policy
}

\author{
Brian D. Fath ${ }^{\mathrm{a}, \mathrm{b}, *}$, Harald Asmus ${ }^{\mathrm{c}}$, Ragnhild Asmus ${ }^{\mathrm{c}}$, Dan Baird ${ }^{\mathrm{d}}$, Stuart R. Borrett ${ }^{\mathrm{e}}$, \\ Victor N. de Jonge ${ }^{\mathrm{f}}$, Alessandro Ludovisi ${ }^{\mathrm{g}}$, Nathalie Niquil ${ }^{\mathrm{h}}$, Ursula M. Scharler ${ }^{\mathrm{i}}$, Ulrike Schückel ${ }^{\mathrm{j}}$, \\ Matthias Wolff ${ }^{\mathrm{k}}$ \\ ${ }^{a}$ Department of Biological Sciences, Towson University, Towson, MD, USA \\ ${ }^{\mathrm{b}}$ Advanced Systems Analysis Program, International Institute for Applied Systems Analysis, Laxenburg, Austria \\ ${ }^{\mathrm{c}}$ Alfred Wegener Institute, Helmholtz Zentrum für Polar- und Meeresforschung, Wattenmeerstation Sylt, List, Germany \\ ${ }^{\mathrm{d}}$ Department of Botany and Zoology, University of Stellenbosch, Stellenbosch, South Africa \\ ${ }^{\mathrm{e}}$ Department of Biology and Marine Biology and Center for Marine Science, University of North Carolina Wilmington, Wilmington, NC, USA \\ ${ }^{\mathrm{f}}$ Institute of Estuarine and Coastal Studies/IECS, The University of Hull, Hull, United Kingdom \\ ${ }^{\mathrm{g}}$ Dipartimento di Chimica, Biologia e Biotecnologie, Università degli Studi di Perugia, Perugia, Italy \\ ${ }^{\mathrm{h}}$ Unité Biologie des Organismes et Ecosystèmes Aquatiques (BOREA), MNHN, CNRS, IRD, Sorbonne Université, Université de Caen Normandie, Université des Antilles, \\ CAEN, France \\ ${ }^{\mathrm{i}}$ School of Life Sciences, University of KwaZulu-Natal, Westville Campus, Durban, South Africa \\ ${ }^{\mathrm{j}}$ Landesbetrieb für Küstenschutz, Nationalpark und Meeresschutz Schleswig-Holstein, Nationalparkverwaltung, Tönning, Germany \\ ${ }^{\mathrm{k}}$ Leibniz Center for Tropical Marine Research (ZMT), Bremen, Germany
}

\section{A R T I C L E I N F O}

\section{Keywords:}

Ecological network analysis

Cycling

Trophic length

Marine and coastal environment

Food web

\begin{abstract}
A B S T R A C T
In this paper, we identified seven ecological network analysis (ENA) metrics that, in our opinion, have high potential to provide useful and practical information for environmental decision-makers and stakeholders. Measurement and quantification of the network indicators requires that an ecosystem level assessment is implemented. The ENA metrics convey the status of the ecological system state variables, and mostly, the flows and relations between the various nodes of the network. The seven metrics are: 1) Average Path Length (APL), 2) Finn Cycling Index (FCI), 3) Mean Trophic level (MTL), 4) Detritivory to Herbivory ratio (D:H), 5) Keystoneness, 6) Structural Information (SI), and 7) Flow-based Information indices. The procedure for calculating each metric is detailed along with a short evaluation of their potential assessment of environmental status.
\end{abstract}

\section{Introduction}

Ecological network modelling and analysis is used to characterize and compare the organization and functioning of ecosystems, and it is most often applied to study food webs (Ulanowicz, 1986; Baird and Ulanowicz, 1993; Fath and Patten, 1999; Borrett et al., 2018). A strength of Ecological Network Analysis (ENA) is the generation of multiple whole-network metrics that may be useful for food web assessment and management (Niquil et al., 2012; Tomczak et al., 2013; Heymans et al., 2016; Heymans and Tomczak, 2016; Lau et al., 2017; de Jonge et al., 2012, accepted). The Schleswig-Holstein Agency for Coastal Defence, National Park and Marine Conservation and the Alfred-Wegener-Institut Helmholtz-Zentrum für Polar-und Meeresforschung Wattenmeerstation hosted a workshop on ENA from 25 to 27 September 2017 on the barrier Island of Sylt between the North Sea and the Wadden Sea. The focus of the workshop was to determine how to reach a broader audience, specifically environmental managers and decision-makers, with network tools and perspectives.

To reach this broader audience, it was evident that the managers must be amenable and receptive to the 'ecosystem approach'. We also recognized that because it is holistic and comprehensive it requires an expensive and elaborate data gathering approach, which may or may not have already been part of the standard monitoring. Therefore, if only quick and crude answers are solicited for individual species or interactions, perhaps this is not the best approach. However, history shows that fragmented solutions from reductionistic approaches that do not take ecosystem effects into account tend to spawn numerous unpleasant and unintended consequences (e.g., fossil fuels as energy source led to climate change, fertilizers for agriculture led to eutrophication, CFC as a refrigerant led to ozone depletion, etc.). The

\footnotetext{
* Corresponding author. Department of Biological Sciences, Towson University, Towson, MD, USA.

E-mail address: bfath@towson.edu (B.D. Fath).
} 
benefits of an ecosystem approach are further considered here, and we take for granted that managers appreciate the advantages of such comprehensive approaches as they facilitate understanding of ecosystem function. Therefore, management aims toward viable ecosystems and the sustainability of ecosystem services. However, such approaches are not always easy to understand or implement in management (Helsenfeld and Enserink, 2008), and this prompted the authors to provide information on how to use a network approach for this purpose.

The field of ecosystem service indicators is well developing (e.g., Layke et al., 2012; Vo et al., 2012; van Oudenhoven et al., 2018), partially due to their prominence in the Millennium Ecosystem Assessments (MEA, 2005; Acosta et al., 2016). The provisioning of such services depends on functioning ecosystems, and this functionality may be indicated and explained through ecosystem network metrics. Biotic and abiotic ecosystem parts, their interlinkages and connectivity to other ecosystems provide the information to calculate numerous metrics, which have been broadly described in the literature in terms of their descriptive capacity of ecosystem functioning, health, development, or state in general. The applicability of these metrics to characterize ecosystems is underpinned by theory (e.g., Odum, 1969; Patten, 1978; Ulanowicz, 1986). However, to facilitate their incorporation into management, they need to fulfill certain criteria to become robust indicators. This includes sensitivity to change, having a sound theoretical basis, describing directional change, being easily communicable to managers and policy makers, and being integrative and indicative to a known response to a disturbance (Dale and Beyeler, 2001).

The workshop was structured around framing presentations about the current state of ecological network analysis in marine systems. These were followed by break-out sessions to brainstorm on specific network indicators and to select the most useful and appropriate for application in marine ecosystem management. We first started with a long, but not exhaustive, list of network indicators (Table 1, for a more comprehensive list of network indicators see Borrett and Lau, 2014 or Kazanci and Ma, 2015). From this break-out session emerged a short list of 7 network indicators (Table 2) that all build on the basic properties of ecosystem networks such as flow, connections, throughflow, and biomass. Another plenary session was used to discuss in depth the definition and meaning of these indicators specifically as though they would be communicated to a decision-maker. That session was organized around the following question:

"The objective of this discussion is to put ENA in a management perspective and to discuss how, and if, (selected) ecosystem indices provide insight into ecosystem functioning and ecosystem services, which are collectively a function of complex interactions among species

Table 1

Step one. List of network properties that emerged from workshop brainstorming session.

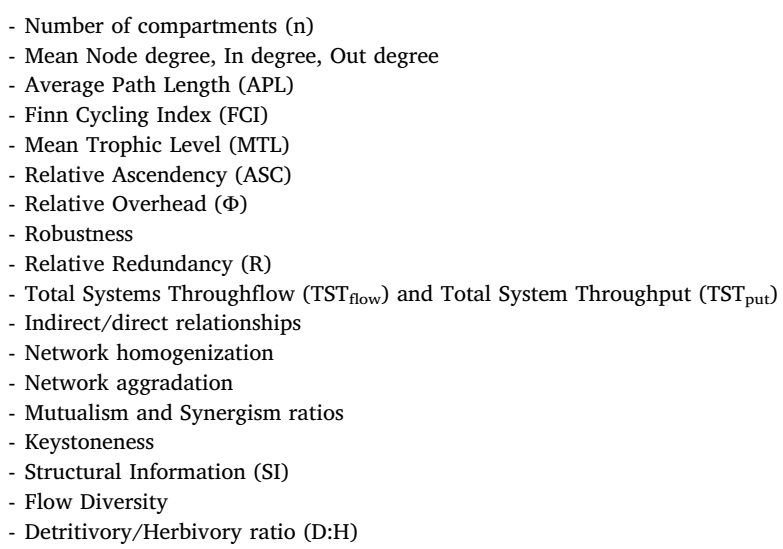

- Number of compartments (n)

Mean Node degree, In degree, Out degree

Total Systems Throughflow ( TST $_{\text {flow }}$ ) and Total System Throughput $\left(\mathrm{TST}_{\mathrm{put}}\right.$ )

Indirect/direct relationships

Network homogenization

Keystoneness

Flow Diversity

- Detritivory/Herbivory ratio (D:H)

Table 2

Step two. Refined list of network indicators as having most relevance and importance for decision makers implementing an ecosystem approach, with primary reference for each - see below for more detail on each metric.

$\begin{array}{ll}\text { 1. Average Path Length (APL) } & \text { Finn (1976) } \\ \text { 2. Finn Cycling Index (FCI) } & \text { Finn (1980) } \\ \text { 3. Mean Trophic Level (MTL) } & \text { Pauly et al. (1998) } \\ \text { 4. Detritivory Herbivory ratio (D:H) } & \text { Ulanowicz and Kay (1991) } \\ \text { 5. Keystoneness } & \text { Libralato et al. (2005) } \\ \text { 6. Structural Information (SI) } & \text { Ludovisi (2009) } \\ \text { 7. Flow-based Information indices } & \text { Ulanowicz et al. (2009) }\end{array}$

and their abiotic environment. Is it possible to identify an index, or a suite of indices, useful for management purposes? This follows from the broader question: Can the indices be operationalized? In other words, are the metrics responsive enough to serve as indicators of change and thereby inform decision-makers how to better manage their systems?"

This paper is a summary of those results. The first section is an overview of the network mathematics used later in the paper. This is followed by a description and application of each of the indicators in the management sphere, ending with a discussion of the application of each metric for environmental management, specifically, ocean and coastal management.

\section{Background to networks}

Every system of compartments and connections can be realized as a network of nodes and arcs. There are numerous papers providing an overview to the network methods described herein. We refer the reader to Ulanowicz (1986), Fath and Patten (1999), and Fath et al. (2007). A brief overview is given here to provide a common notation for discussion within this paper. Consider a network with $\mathrm{n}$ compartments or nodes, which can be represented as $x_{i}$, for $i=1$ to $n$. The flow or transaction of the energy-matter substance moving from node i to node $\mathrm{j}$ is given by $\mathrm{f}_{\mathrm{ij}}$ and can be arranged into a matrix $\mathbf{F}$ containing all pairwise flows in the network. ${ }^{1}$ In addition, these ecological or environmental systems are open to receive new input and thus generate also new output. Such flows that cross the system boundary are labelled $z_{i}$ and $y_{i}$, for $i=1$ to $n$, respectively. In some ecosystem studies, $y_{i}$ is divided into export $\left(e_{i}\right)$ and respiration $\left(r_{i}\right)$ flows because the former is useable material outside the system, whereas the latter is heat lost which is unable to due further work. Knowing the total amount of material or energy moving through each node and the entire network is an important indicator of the scale of activity within that system. From the flow matrix and input/outputs, we can find this total activity going through any node as either the sum of all the flows into the node or all the flows out of the node.

$T_{i}^{i n}=z_{i}+\sum_{j=1}^{n} f_{j i}$

$T_{i}^{\text {out }}=y_{i}+\sum_{j=1}^{n} f_{i j}$

At steady state,

$T_{i}^{\text {in }}=T_{i}^{\text {out }}=T_{i}$

The Total System Throughflow ( $\mathrm{TST}_{\text {flow }}$ ) is the sum of all the individual nodal flows, given by:

$\operatorname{TST}_{\text {flow }}=\sum_{i=1}^{n} T_{i}$

\footnotetext{
${ }^{1}$ In some of the literature the flows are arranged from node $\mathrm{j}$ to node $\mathrm{i}$ for ecological reasons.
} 
This differs from the measure of Total System Throughput ( $\mathrm{TST}_{\mathrm{put}}$ ) which is the sum of all nodal inflows and outflows, including the boundary flows (or sum inputs):

$T S T_{p u t}=\sum_{j=1}^{n} z_{j}+\sum_{i=1}^{n} \sum_{j=1}^{n} f_{i j}+\sum_{i=1}^{n} y_{i}$

The main difference is that $\mathrm{TST}_{\text {put }}$ includes both the input and output plus the internal flows, whereas $\mathrm{TST}_{\text {flow }}$ is the sum of all the inflows or the sum of all the outflows (this avoids double counting the same flow as inflows and also as outflows). One advantage of the TST $\mathrm{put}_{\text {approach }}$ is that it is not required for the system to be in steady state to calculate it (but see also de Jonge et al. accepted A who demonstrate that balancing of the flows of living and non-living compartments or nodes is always preferred). Note that by definition $T S T_{\text {put }} \geq T S T_{\text {flow }}$.

As stated above, node throughflow $\left(T_{i}\right)$ is the contribution of each node to the system activity. When the network model represents a food web, $T_{i}$ is equivalent to the gross production of the node (Ulanowicz and Puccia, 1990), and when the model currency is energy, $T_{i}$ has been interpreted as the node power in thermodynamic terms (Patten, 1995). Further, it can be used as a global centrality metric that indicates the relative importance of each node in a system (Borrett, 2013). TST $_{\text {flow }}$ and $\mathrm{TST}_{\text {put }}$ are then network-level indicators of the size and activity of the system, and depending on the model specifics they indicate the amount of production or power the system contains (Finn, 1976; Ulanowicz and Norden, 1990).

The flows in the Flow matrix (F) capture the direct transactions, but network analysis can be used to determine indirect flow paths and influences as well. Indirect impacts refers to flows between nodes that are not in direct exchange but that influence each other through paths of length 2 or greater. The matrix algebra of network analysis allows us to calculate these indirect contributions, accordingly when the network is at steady state. First, we calculate a non-dimensional, output oriented flow intensity matrix designated by $\mathbf{B}$, where $b_{i j}=f_{i j} / T_{i}$. A complementary input-oriented non-dimensionalized flow matrix can also be constructed, where $b_{i j}^{\prime}=f_{i j} / T_{j}$. Ecological Network Analysis (ENA, see Fath and Patten, 1999) tells us that taking powers of this matrix gives the flow intensities along path lengths commensurate with the power, i.e., $\mathbf{B}^{2}$ are two-step pathways, $\mathbf{B}^{3}$ three-step, etc. Another important discovery of ENA is that it is possible to simultaneously consider all powers in one term by summing the infinite series which converges to a composite matrix, we call, $\mathbf{N}$, such that

$N=\sum_{m=0}^{\infty} B^{m}=B^{0}+B^{1}+B^{2}+B^{3}+B^{4}+\ldots$

The $\mathrm{N}$ matrix is termed the integral flow matrix because it sums or integrates the flow along the direct and all indirect pathways. Due to the open and dissipative thermodynamic nature of ecosystems and food webs, the infinite series in eq (6) converges. The exact value of this convergent infinite series is given by the identity in eq (7), which highlights the similarity of the $\mathrm{N}$ matrix to the Leontief inverse in economic input-output analysis (Hannon, 1973).

$N=\sum_{m=0}^{\infty} B^{m}=(I-B)^{-1}$

These basic network building blocks identifying direct and indirect pathways are used to develop the specific network metrics described below.

\footnotetext{
${ }^{2}$ Specific is the last aspect of ROARS and the first of SMART, and is only presented once here.

${ }^{3}$ We have omitted the last aspect of SMART, Time-bound, which does not seem relevant here, but have instead included the characteristic if it is communicable.
}

\section{Network metrics}

\subsection{Average path length}

Average Path Length (APL) is defined as the total system throughflow divided by the total boundary input into the system (Finn, 1976):

$A P L=\frac{T S T_{\text {flow }}}{\sum_{i=1}^{n} z_{i}}$

In Finn's original interpretation (1976), this is the average number of paths a given unit of input (often carbon) will travel in the system before exiting the system. More generally, it is an indicator of the amount of system activity (TST flow) generated by each unit input into the system. Since cycling contributes to overall system flow, a higher degree of cycling equates to a larger APL. Thus, it is an indicator of the organization of the system and the system's ability to do more work with given resources (the boundary input). This is why Jørgensen et al. (2000) interpreted it as an indicator of system growth and development, which they renamed network aggradation.

\subsubsection{Relevance for stakeholders}

Assuming that most resource flows are scarce, the more impact each unit of boundary flow has within a system, the more the system will benefit. APL is easy to measure and calculate. It is intuitively easy to understand and communicate the meaning to others. For example, in ecological terms the indicator shows that the higher the boundary flows are, the more external carbon or other currency is available for an ecosystem. In this situation, APL will be lower when the internal $\mathrm{TST}_{\text {flow }}$ remains stable. In contrast, if the internal $\mathrm{TST}_{\text {flow }}$ increases when the boundary inputs stay the same, then the system organization has developed in a way to make more or better use of the initial resource input. In economic terms, this is conceptually similar to the multiplier effect, which is a measure of how many times a unit of currency that enters into a market will be exchanged before exiting that market. The market boundaries are akin to the network system boundaries. High multiplier values indicate healthy levels of cross-scale circulation and a robust internal economy. APL is expected to be higher in systems with higher diversity of flows and cycling (Christensen, 1995) and decrease in the face of stress as found by Tecchio et al. (2015) and Schückel et al. (2015). In ecosystems, a higher APL value does not necessarily indicate health, but the ability to generate flows within the system per a given boundary input. Changes in this relation may indicate increased or decreased boundary flows, or changes in the flow structure of the system, or both.

\subsection{The Finn Cycling Index}

Finn (1976, 1980) proposed a method to calculate precisely the fraction of the total system throughflow $\left(\mathrm{TST}_{\text {flow }}\right.$ ) that is cycled in the network, in other words, how much of the flow would revisit the same node multiple times before exiting the system. Cycled flow of node $i$ $\left(T S T c_{i}\right)$ can be calculated by the following formulation:

$\operatorname{TSTc}_{i}=\left(\left(n_{i i}-1\right) / n_{i i}\right) T_{i}$

Finn Cycling Index can be calculated by the total cycling throughflow divided by total system throughflow:

$F C I=\frac{\sum T S T c_{i}}{T S T_{\text {flow }}}$

\subsubsection{Relevance for stakeholders}

Cycling is tied to the average path length (APL) because greater cycling is one mechanism to increase TST without increasing boundary inputs. Increased cycling means that the energy or material stays in the system longer. For resources that have a positive impact on the system, 
cycling indicates that the internal flow organization allows for some degree of self-reliance (Ulanowicz, 1983). Other cases show a stressed system also exhibits higher levels of cycling (Scharler and Baird, 2005; Tecchio et al., 2015). Systems with a low FCI but high throughflow are dependent on boundary flows to sustain a high level of throughflow (e.g., agricultural systems, systems that receive lots of waste (POC and DOC) such as Dollard in de Jonge et al. accepted and de Jonge and Schückel, submitted to OCMA). Flows across the system boundary, in addition to the inner system structure, are therefore important determinants of whether changes in FCI are within a natural variability (stochastic impact of diurnal, seasonal, or ecological parameters), or may indicate a change in system state. Although the property is dimensionless, some researchers urge caution when comparing FCI across systems (Heymans et al., 2014) because the chosen degree of aggregation of cycling during the network construction process influences the extent of the cycling.

\subsection{Mean trophic level (MTL), mean trophic level of the catch (MTLC)}

The trophic level of an organism is the average position it occupies in a food chain. Food chains start at trophic level 1 with primary producers such as plants, move to herbivores at level 2, and predators at level 3 and typically finish with carnivores or apex predators at level 4 or 5. The path along the chain can form a one-way food "flow" (chain), or a food "web" Highly evolved and unstressed systems often have higher abundances and biomasses of high trophic level species. Most ecosystems feature considerable levels of omnivory, where omnivores feed on different trophic levels and therefore occupy themselves a trophic level somewhere in between (Raoux et al., 2018). The trophic level, TL, for any consumer species (i) is calculated as:

$T L_{i}=1+\sum_{j}\left(T L_{j} * D C_{i j}\right)$

where, $\mathrm{TL}_{\mathrm{j}}$ is the fractional trophic level of the prey $\mathrm{j}$, and $\mathrm{DC}_{\mathrm{ij}}$ represents the fraction of $j$ in the diet of $i$.

The Mean Trophic Level of a system is calculated from the trophic positions of each system compartment and its relative contribution to the system biomass:

$M T L=\frac{\sum_{i}\left(B_{i} * T L_{i}\right)}{\sum_{i} B_{i}}$

where $B_{i}$ and $T L_{i}$ are the biomasses and trophic levels of each of the contributing groups (i) of the system (Branch et al., 2010, Shannon et al., 2014).

While we recommend the use of MTL as a holistic indicator of the ecosystem functioning, the mean trophic level is often difficult to estimate. It is often easier to calculate the Mean Trophic Level of the Catch, which is usually comprised of some species only, for which the landed biomass is, moreover, easily determined. For its calculation the yield replaces the biomass in the above formula:

$M T L C=\frac{\sum_{i}\left(Y_{i} * T L_{i}\right)}{\sum_{i} Y_{i}}$

and $\mathrm{Y}_{\mathrm{i}}$ and $\mathrm{TL}_{\mathrm{i}}$ are the yields and trophic levels of the species that comprise the catches. Furthermore, the indicator is sensitive to the way the ecosystem is partitioned into functional groups (i.e., model topology), therefore the field will benefit with common and good standards in network creation (see e.g., Fath et al., 2007).

\subsubsection{Relevance for stakeholders}

This index is often (see, e.g., Pauly et al., 1998) used in the assessment of sustainability in fisheries as its decrease over time this is considered to reflect the phenomenon of "fishing down the food web", since fishing pressure depletes top-predators more severely than lowtrophic level species. This concept, which assumes that the catch composition reflects general trends in the considered ecosystem, has been adopted by the Convention of Biological Diversity (CBD) to be "ready for global use" (BDI Partnership, 2010). However, factors that determine the trophic composition of landings are complex and it may well be that a simple catch increase in low-trophic level species leads to lower MTLC values, while the top predator populations may still be doing well (see Essington et al., 2006). MTL estimates derived from sound ecosystem surveys may provide a good picture of the ecosystem state. In this case, a higher MTL of an ecosystem indicates a higher proportion of higher trophic level species, which is in concordance of ecosystem succession to include comparatively more k-strategists (larger, slower growing species) as part of the ecosystem. The loss of toothed whales, large carnivorous sharks and fish, for instance, would decrease the MTL, and such a decrease could also be achieved by eliminating carnivorous fauna within any other invertebrate or vertebrate group.

\subsection{Detritivory: herbivory (D:H) ratio}

MTL describes how the consumers organize into food chains of various lengths, but does not describe to what extent these chains rely on the first trophic levels for energy and nutrients. The second trophic level of a food web can rely on two feeding modes, herbivory and detritivory. Herbivory is the consumption of autotrophic organisms, which are responsible for the carbon incorporation into the ecosystem through the process of photosynthesis, provide an important link between inorganic dissolved nutrients and biomass. These autotrophic organisms are in turn consumed by herbivorous consumers (grazers). Detritivory is the consumption of non-living organic matter, which can be composed of locally produced matter, through the processes of egestion and mortality, or it can be from allochthonous origin, through the process of importation of non-living material from adjacent environments (Postma, 1967). In most models, this non-living matter is either gathered into one compartment or separated into size-based or habitat-based compartments (e.g., Allesina et al., 2005). For example, to show the impact of classifying detritus, we refer to some specific studies. The "particulate detritus" or "particulate organic matter" is usually composed of the matter whose size is practically greater than $0.7 \mu \mathrm{m}$, and the "dissolved organic matter" is composed of those less than $0.7 \mu \mathrm{m}$ (see Strickland and Parsons, 1972; Grasshoff et al., 1983). The lower size limit corresponds to the lower pore diameter of, e.g., the GFF filters, GFC filters, or Millipore filters as widely used in oceanographic research. The compartment "particulate organic matter" (POC) should be divided into "suspended" (susPOC) and "sediment" particulate organic matter (sedPOC) since POC alternately can occur as sediment or be resuspended in association with inorganic sediment (e.g., Postma, 1967, de Jonge et al., 1995) and sediment inhabiting microalgae (de Jonge et al., 1995; de Jonge and van Beusekom, 1995).

To calculate the $\mathrm{D} / \mathrm{H}$ ratio, the sum of all flows from non-living compartments within the system to consumers are divided by the sum of flows from all autotrophic compartments to consumers. Only internal consumers are considered (those belonging to the considered system). This can be done either using the matrix of flows directly or using the Lindeman (1942) spine. A Lindeman spine is a linear chain, summarizing the food web, were each species is allocated to a discrete level (Baird and Ulanowicz, 1993). Because autotrophs and non-living detrital pools are separated at the first trophic level, the Lindeman spines identifies the flows entering the food web, originating from these 2 sources. In the example of two subsystems of the Sylt-Rømø Bight given in Fig. 1 (Baird et al., 2007), the flow of detritivory is $1523 \mathrm{mgC} \mathrm{m}^{-2}$ $\mathrm{d}^{-1}$ in the mussel bed and $550 \mathrm{mgC} \mathrm{m}^{-2} \mathrm{~d}^{-1}$ for the Arenicola flat, and herbivory is respectively 5350 and $599 \mathrm{mgC} \mathrm{m}^{-2} \mathrm{~d}^{-1}$ resulting in a D/ $\mathrm{H}$ ratio of 0.28 and 0.9 , respectively. For the full food webs of three main reaches (Lower, Middle, Dollard) representing the main part of the Ems estuary, de Jonge et al. (accepted) found values ranging from 3.1 (Lower) - 4.3 (Middle) - 9.0 (Dollard) from the sea in an upstream 

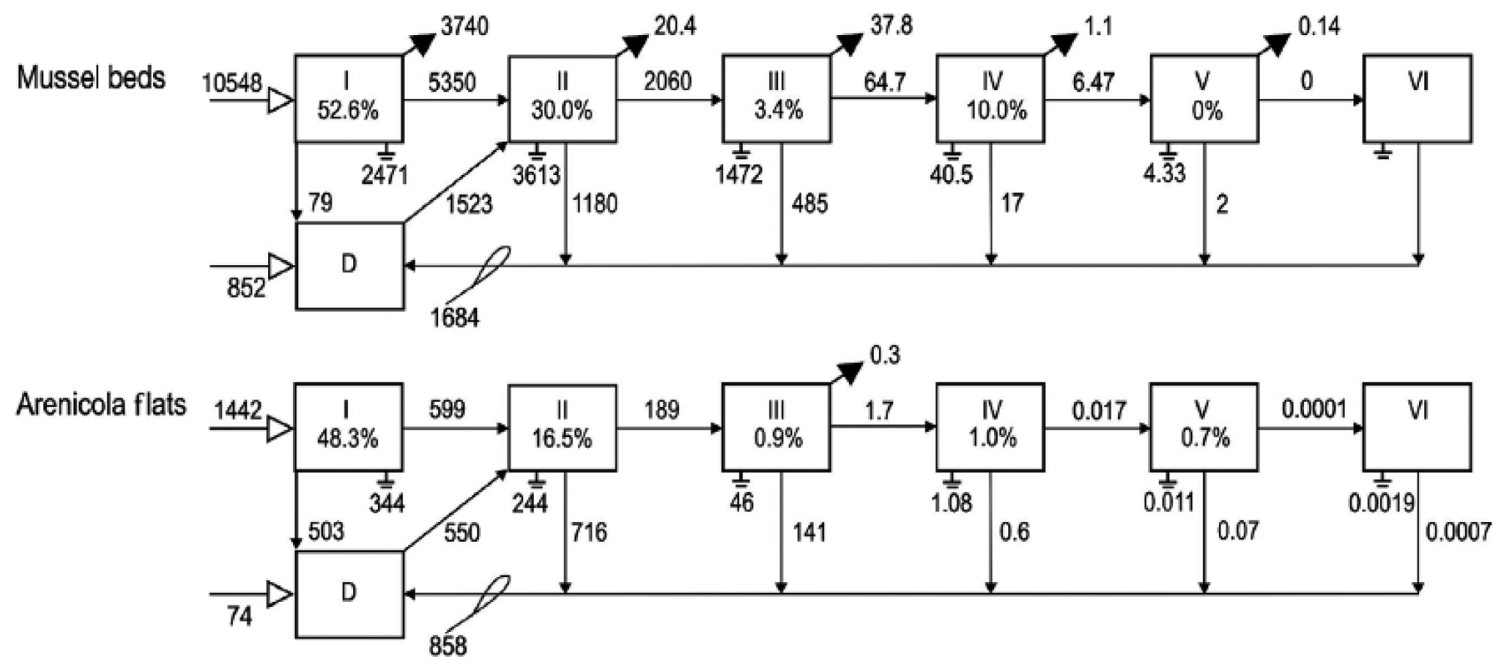

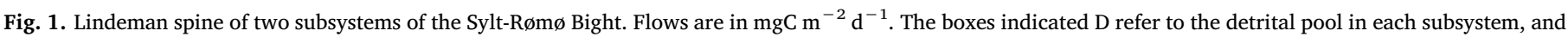

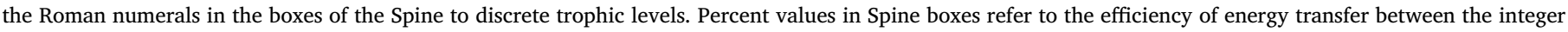
trophic levels. From Baird et al., 2007.

direction indicating greater reliance on detritus based resources moving inward.

\subsubsection{Relevance for stakeholders}

Wiegert and Owen (1971) were first to publish on the importance of two parallel pathways fueling the food webs, one which relied on the consumption of living organisms (grazing-predation base) and the other on the consumption of non-living material (detrital base). The $\mathrm{D} / \mathrm{H}$ ratio is a means to describe which one of these two sources dominates. Some examples show that the ratio $\mathrm{D} / \mathrm{H}$ reflects the availability of primary producers as a food source, with higher herbivory (low $\mathrm{D} / \mathrm{H}$ ) being associated with higher primary production (e.g., Chrystal and Scharler, 2014, de Jonge et al. accepted), but this is not always the case. The example of the graminoid marshes ecosystem of the South Florida Everglades (Heymans et al., 2002) shows that a high D/H ratio can also be associated with a high primary production, when the plant material is not consumed directly, but only after breaking down and forming detritus. The measure is also high in cases when POC and DOC is transported into the system from algae production elsewhere - as is the case in the Florida Everglades and North Sea estuaries such as the Ems estuary. This demonstrates the need for using this index in complement to flow information (e.g., primary production) to ascertain the relative importance of flows from primary producers and non-living modes. Odum (1969) describes the evolution of ecosystems from a linear chain to a complex web where flows do not rely only on direct primary producers but also on indirect detritus consumption. For this reason, detritivory has been considered as an indicator of maturity (Christensen, 1995).

\subsection{Keystoneness}

There are multiple definitions of keystones in the ecological literature (Valls et al., 2015) with the main concept being that certain species play a particular role that is fundamental in structuring an ecosystem or exerts a strong impact on its function. Paine (1969) defined keystoneness as species with a relatively small range of biomass that influences the community structure by its predation on other species and thus has an outsized effect on diversity on community structure, functioning, and function. Ecosystem engineers, on the other hand, alter the abiotic environment and thus enable many other organisms to develop a community that is adapted to these special conditions (Jones et al., 1994). Organisms such as reef building corals, bivalves, or macrophytes often form large aggregations and dominate a community in biomass or abundance attracting many organisms to settle because of offering shelter, food, and substrate. In this way, the organisms provide opportunity for new organisms in a self-reinforcing cycle that promotes biodiversity (Cazzolla Gatti et al., 2018). These engineers, although of great relevance in terms of ecosystem structuring, are generally not considered keystone species due to their high biomass.

Keystoneness has been identified on both a qualitative and a quantitative bases. In experimental studies, mainly qualitative criteria such as the impact of a predator on species richness and species presence/absence were used to assess this special role (Paine, 1994; Menge, 1995; Power et al., 1996; Estes et al., 1998). Since keystone species for a given system may change in space and time, the concept was criticized, and a general and consistent definition was postulated (i.e., Mills et al., 1993; Bond, 2001). To support this effort, quantitative aspects of the definition were applied especially in energy flow models such as EcoPath (Ulanowicz and Puccia, 1990; Christensen and Pauly, 1992) or Ecological Network Analysis (ENA) (Fath and Patten, 1999; Jordán, 2009) or some dynamic applications of these modelling tools such as Ecopath with Ecosim (EwE) (Libralato et al., 2005; Heymans et al., 2014; Valls et al., 2015).

Within these models the trophic niche overlap of certain species was defined and formulated as an index. While there are a few different approaches to calculate keystoneness, here, we use the one by Libralato et al. (2005), which combines the indirect network relations proportional to the total biomass (i.e., big effects are offset if the biomass is also big). This approach relies on the network-based methods described above:

$K S=\log \left[\varepsilon_{i}\left(1-p_{i}\right)\right]$

where,

$\varepsilon_{i}=\sqrt{\sum_{i \neq j} m_{i j}^{2}}$

where, $\mathrm{m}_{\mathrm{ij}}$ are the elements of the mixed trophic impact matrix (Ulanowicz and Puccia, 1990).

The parameter $p_{i}$ relates to the relative biomass of species $i$ with respect to the total biomass of all the components in the food web and is calculated from the following:

$p_{i}=\frac{B_{i}}{\sum_{k=1}^{n} B_{k}}$

In ENA the mixed trophic impact analysis was formulated as a special tool that compares the impacts a certain species has on all food 
web compartments (Ulanowicz and Puccia, 1990). Related to the target species the mixed trophic impact can be positive or negative. The target species can be involved in both direct (such as predation) or indirect (cascading, competition) processes and can thus exert bottom up or top down effects by positive and negative interactions (Bondavalli and Ulanowicz, 1999). This technique is useable to any "focal" species, but for the identification of a keystone species further selection criteria are needed. Although keystone species have been defined as those whose effect is disproportionately large relative to their abundance (Power et al., 1996), it appears that a threshold of abundance and time must be reached to result in strong cascading community effects (Konar, 2000).

\subsubsection{Relevance for stakeholders}

Food webs display the myriad interactions of different species or groups by their trophic interactions. These interactions relate to direct feeding or indirect feeding via cascading effects. Ranking species with the highest proportion of overlap identifies those exerting the highest impact on others in the ambient food web or ecosystem. If this degree of overlapping is combined with a relatively low biomass, then we can measure the interaction strength between a target species and all other species and denominate this particular species as a keystone species (Araújo et al., 2011). From a stakeholders' perspective, a keystone species may be of particular interest for conservation or sustainable management efforts, knowing, in fact, that the 'species oriented' keystone emerged from an analysis of whole ecosystem interactions.

Entropy based indicators. From a thermodynamic standpoint, ecosystems can be viewed as self-organizing systems able to maintain themselves in a far-from-equilibrium condition by exploiting the entropy exchanges with the surrounding environment (Nicolis and Prigogine, 1977; Schrödinger, 1944; Ulanowicz and Hannon, 1987). A flow of low-entropy energy is needed in order to sustain the selforganization of organisms, the trophic network and the matter cycling (Morowitz, 1968). Several entropy/information-based functions have been proposed as ecological indicators and/or orientors (Fath et al., 2004; Jørgensen et al., 2007) and they have been used to describe the developmental state of an ecosystem, as well as its complexity. Among them, we can mention Structural Information (Ludovisi, 2009) and flow-based information indices Average Mutual Information and related indicators such as Flow Diversity and Overhead (Ulanowicz, 1986).

\subsection{Structural Information}

Structural Information (SI) refers to the food web relations and connections, such that a more complex structure (more feeding pathways and levels - see Fig. 2) has more information. One approach to measure this has been derived within the framework of the exergy concept. Starting from the basic formulation of exergy for ecosystems (Mejer and Jørgensen, 1979):

$E x=R T \sum_{i=1}^{n} c_{i} \ln \frac{c_{i}}{c_{i(e)}}-\left(c_{i}-c_{i(e)}\right)$

where $R$ is the gas constant, $T$ the absolute temperature and $c_{i}$ the concentration of the $i$-th ecosystem component in suitable units (with the subscript $e$ indicating the reference equilibrium state). Ludovisi (2009) proposed to express exergy as a function of three terms, as follows:

$E x=R T\left[C \sum_{i=1}^{n} p_{i} \ln \frac{p_{i}}{p_{i(e)}}+\left(C \ln \frac{C}{C_{(e)}}-\left(C-C_{(e)}\right)\right)\right]$

where $C=\Sigma_{i} c_{i}$ is the total concentration of components, $p_{i}=c_{i} / C$ is the relative abundance of the $i$-th component.

The three terms of the expression are the total concentration of components (the size term, $C$ ), a term accounting for the change in the

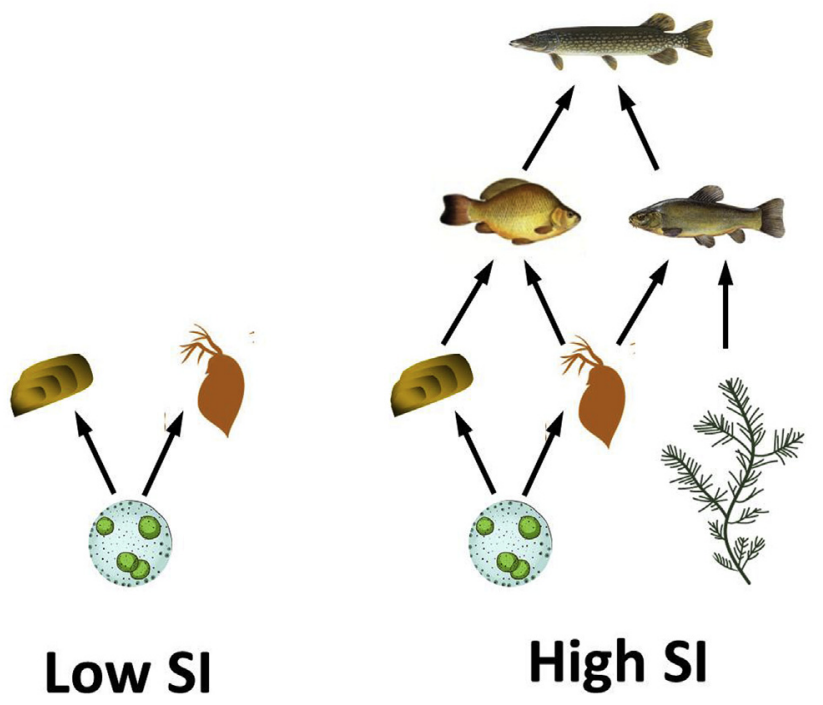

Fig. 2. Structural Information increases with increasing abundance of largesized species, which mostly appear at high trophic levels.

total concentration of components (the concentration term, $X$ ), and the Structural Information (SI), which expresses the relative information arising from the change in the matter apportionment between equilibrium (the reference state) and the actual state. The calculation of the terms of the equation requires that the equilibrium concentration $\left(c_{i}\right)$ of all the relevant ecosystem components are estimated. The estimate of these values for organisms and particulate organic matter in general represents the most troublesome step of the calculation. To face this issue, Ludovisi (2009) suggested applying the condition of thermodynamic equilibrium to the ultimate reaction (e.g., oxidation) which leads a system to thermodynamic equilibrium. Such a calculation leads to virtual equivalent concentration at equilibrium (VECE) values, which are inversely dependent on the body size of organisms. For example, in a surface water environment, the VECE values can be estimated as $10^{-12}$ cells $1^{-1}$ for bacteria and $10^{-26}$ Ind. $1^{-1}$ for fish.

Therefore, the three terms of the exergy, and particularly SI, are strongly dependent on community composition, especially in terms of size spectrum, community structure, and diversity (Fig. 2). Since largesized organisms typically dominate in late stages of ecological succession (Odum, 1969), SI is expected to increase along with ecosystem development. The soundness of SI as ecological orientor has been shown in theoretical studies (Jørgensen et al., 2010; Ludovisi, 2009; Ludovisi and Jørgensen, 2009), and its effectiveness as ecological indicator has been tested by application to simulated (Ludovisi, 2009) and real case studies, also in comparison with other thermodynamic orientors (Ludovisi, 2014; Ludovisi et al., 2012).

\subsubsection{Relevance for stakeholders}

Besides contributing to fill the gap between indication based on network composition (type and importance of network compartments) and flow structure (type and importance of flows among compartments), the integration of the above entropy/information measures is also suitable to be implemented for the purposes of the Water Framework Directive (WFD) and the Marine Strategy Framework Directive (MSFD), as the data needed for calculation are collected according to the current standard protocols used for the assessment of the ecological status of water bodies or habitats. In particular, the use of SI could help to overcome drawbacks entailed in the methodologies currently used to assess the ecological state of ecosystems, as explained further below. 


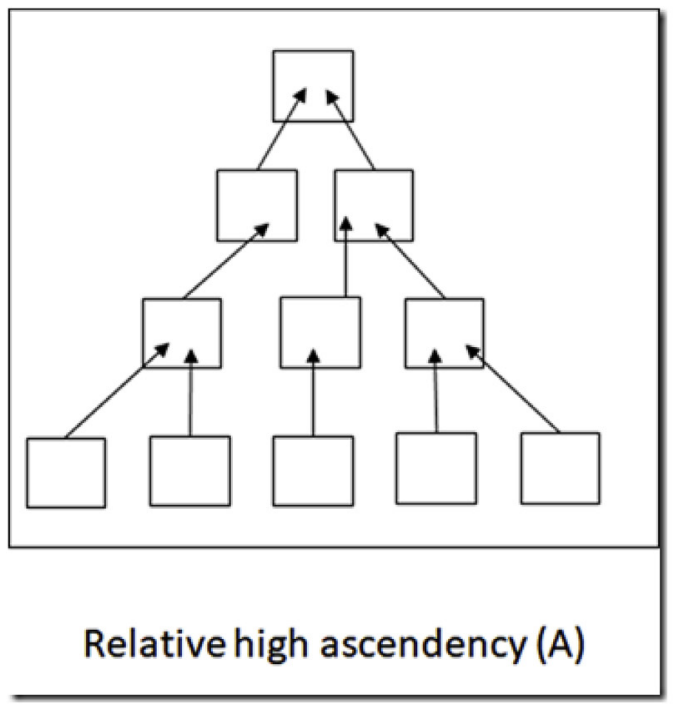

\subsection{Flow-based information indices}

There are several information based indicators that rely on the configuration of flow interactions between pairs of nodes. Here, we consider Flow diversity (H), Development Capacity (DC), Average Mutual Information (AMI), Ascendency (ASC or A), Overhead ( $\Phi$ ), Redundancy (R), and Robustness. These indicators are used to assess the growth and development of an ecosystem, the balance between levels of diversity and flexibility (resilience), and streamlining of energy flows (efficiency). Both measures are combined into one robustness metric using Ulanowicz' Window of Vitality for networks (Ulanowicz et al., 2009). Ulanowicz et al. (2009) showed that the organization of flows in empirical ecosystem networks exhibit a robust trade-off - hypothesized as a result of long-term adaptive and evolutionary pressures - such that an extremely high efficiency, or an extremely high flow redundancy is not reached. Biodiversity, in networks revealed as the number of nodes and flows, and in food web (or other weighted) networks the diversity of connections between nodes, are important concepts for the resilience and efficiency of ecosystems. The flow diversity is calculated by applying Shannon's diversity index to flows (MacArthur, 1955):

$H=-k \sum_{i, j}\left(\frac{T_{i j}}{T_{. .}}\right) \log \left(\frac{T_{i j}}{T_{. .}}\right)$

where $T_{i j}$ denotes a flow from source $i$ to recipient $j, T$.. a summation over flows in the system, and the log is base 2 . Note that in the calculation of all information based flow indices, $\mathrm{T}_{\text {.. }}$ equates to TSTput. Due to the skewed distribution of flow magnitudes in weighted networks, the flow distribution in ecosystem networks is such that about $20 \%$ of flows contribute $80 \%$ to $\mathrm{H}$ (Scharler and Fath, 2012). To scale the diversity index to the size of the ecosystem, $k$ can be replaced with $\mathrm{T}_{\text {.., }}$ which results in the metric Development Capacity (DC):

$D C=-\sum_{i, j} T_{i j} \log \left(\frac{T_{i j}}{T_{. .}}\right)$.

Most often, $\mathrm{T}$.. is several orders larger than $\mathrm{H}$, and consequently variations in the value of $\mathrm{H}$ may be masked by a trend in $\mathrm{T}$.. To focus on trends in the diversity of flows, it is therefore advisable to report $\mathrm{H}$ rather than DC.

A more detailed description of information generated from pairwise interactions of nodes is revealed by the Average Mutual Information (AMI) (Ulanowicz, 1986). The information is generated by the joint probability of a certain flow occurring $\left(\mathrm{T}_{\mathrm{ij}} / \mathrm{T}_{\text {.. }}\right)$, the marginal probability of a flow entering the consumer $\mathrm{j}(\mathrm{T} . \mathrm{j} / \mathrm{T} .$.$) , and the conditional$ probability that $\mathrm{T}_{\mathrm{ij}}$ leaves its source node $\mathrm{i}\left(\mathrm{T}_{\mathrm{ij}} / \mathrm{T}_{. \mathrm{i}}\right)$ (Scharler, 2008). The three different parts join to the AMI index:

$A M I=K \sum_{i, j}\left(\frac{T_{i j}}{T_{. .}}\right) \log \left(\frac{T_{i j} T_{. .}}{T_{i .} T_{. j}}\right)$.

Also, this index may be scaled to the system size by replacing $\mathrm{k}$ with $\mathrm{T}_{. .}$, resulting in the Ascendency (ASC, or A) (Ulanowicz, 1986, 1997):

$A=\sum_{i, j} T_{i j} \log \left(\frac{T_{i j} T_{. .}}{T_{i .} T_{. j}}\right)$

The same considerations apply as to the interpretation of DC, since also this metric consists of two parts with very different magnitudes (AMI and $\mathrm{T}_{\text {..) }}$.

The two metrics $\mathrm{H}$ and AMI are related such that $\mathrm{H}$ reflects the upper boundary to AMI in each ecosystem (Ulanowicz, 1986). There is always a difference between $\mathrm{H}$ and AMI, or DC and ASC, and this difference is important for the resilience of ecosystems. It represents redundant flows, which are additional (parallel) pathways between nodes. These can be calculated for internal flows, respiration, and other boundary flows (imports and exports), collectively called Overhead. The unscaled and scaled version are calculated as follows:

$H_{c}=-k \sum_{i, j}\left(\frac{T_{i j}}{T_{. .}}\right) \log \left(\frac{T_{i j}^{2}}{T_{i .} T_{. j}}\right)$, and

$\Phi=-\sum_{i, j} T_{i j} \log \left(\frac{T_{i j}^{2}}{T_{i .} T_{. j}}\right)$.

This overhead is important to the resilience of a network, as highly efficient ones (high AMI value) are perceived to be prone to disturbance. Redundancy measures the useful array of parallel pathways along which biomass may exchange between the compartments (Ulanowicz, 1986). Due to the larger number of parallel pathways, greater redundancy corresponds to a system that should be able maintain stability when it is perturbed (See Fig. 3 for variation in food webs that display high ascendency versus high overhead).

In fact, the ratio $\mathrm{AMI} / \mathrm{H}$, or $\mathrm{ASC} / \mathrm{DC}$ has been widely used to characterize efficiency, resilience, and even health of ecosystems (Christian et al., 2005; Ulanowicz et al., 2009), and this ratio is known to be resilient to uncertainty in model parameterization (Kaufman and Borrett, 2010). The ratio has subsequently been incorporated into a single measure, a system robustness index, to capture these opposing tendencies in system organization (Ulanowicz et al., 2009). This index has previously been called fitness, but also labelled sustainability, 


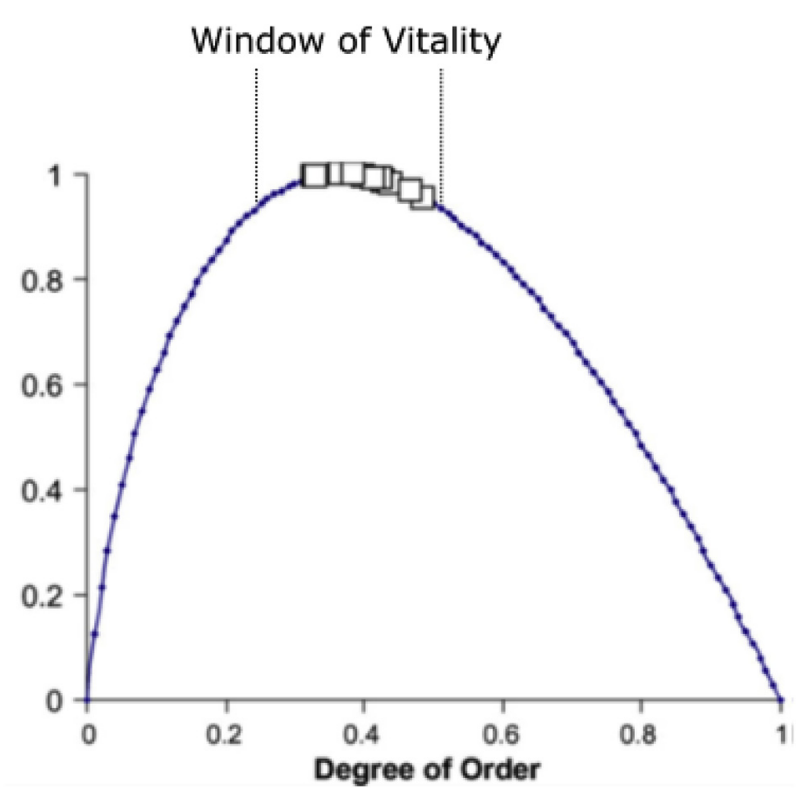

Fig. 4. Theoretical curve showing the information-based approach tradeoff between system efficiency and redundancies (Ulanowicz et al., 2009). Evidence from empirical ecological networks cluster around the optimum range and therefore do not exhibit maximization of efficiency or redundancy.

resilience, and robustness. We prefer the name robustness which has a different connotation than the other terms already used for various other ecological concepts (Fig. 4):

Robustness $=-a \ln a$,

where $a=\frac{A}{D C}$

Empirical networks (see de Jonge et al. accepted B) revealed that ecosystems tend to congregate on top of the resulting curve showing highest robustness values (Fig. 4). This led to an interpretation that viable ecosystems consist of different types of pathways, some of which are efficient, and others that are redundant in the sense of representing parallel, or additional, pathways. Networks with flow constraints that are on the whole intermediate, but consist of efficient and redundant pathways are therefore thought to be optimal.

\subsubsection{Relevance for stakeholders}

Such system level metrics give us additional information to species and community-level indicators and allow to gauge the overall structure and functionality of ecosystems. An increase or decrease in the value of $\mathrm{AMI}, \mathrm{H}$, or $\mathrm{AMI} / \mathrm{H}$ is determined by the individual flows structure, such that changes in large flows result in a larger change of the indices compared to changes in small flows. A change in the indices therefore does not necessarily indicate a change in the health of an ecosystem, unless the metric change is caused by a decrease or extinction of several species producing small flows as opposed to a decrease in large flows (usually originating from bacteria, phytoplankton, or detritus). However, the metrics serve to identify the changing state of a system. Whether a state change is detrimental or beneficial depends on the present state (e.g., natural, impacted), and on which flows caused the change in the metrics (Ludovisi and Scharler, 2017, de Jonge and Schückel submitted). Management actions are in general targeted at the node or species level, and these metrics show the consequences of such actions on the overall ecosystem robustness. For instance through exploratory studies, such actions can be incorporated into the ecosystem to explore whether they will lead its robustness towards efficiency or resilience (e.g., Mukherjee et al., 2015; Ludovisi and Scharler, 2017).

\section{Discussion}

The definition of indicators for describing changes in the functioning of ecosystems has been a central question for researchers in ecology and fisheries sciences during the last two decades. A good indicator should be simple, specific, and sensitive to changes (natural and human induced perturbations) in ecosystems caused by different pressures (eutrophication, dredging, fisheries, etc.) to define the pressurestate change relationships as exemplified by de Jonge and Schückel (submitted, their Figs. 1 and 3). There is usually a clear tension and difference between what policy makers and decision makers ask for to facilitate their work process and what scientists deliver. Management decisions related to ecosystem assessments are more difficult compared with those related to single species assessments, but even then the decision makers need preferably clear-cut suggestions and ways of implementing them. They explicitly do not like to engage with the many versions, uncertainties, exceptions, pros and cons and caveats that scientists are very good in delivering. The difference between the demands and the offers easily leads to confusion and even friction. The crucial point is that, when asked for help, scientists typically stick to their own nuanced and detailed views while the decision makers (and other stakeholders) look for clear cut answers. A better bridge is needed between the two worlds.

Ecosystem based management received a boost when its approach was woven into the Convention of Biological Diversity, which was signed in 1993. There was a subsequent rise in demand for indicators to assess the 'structure' and the 'functioning' of ecosystems linked with the publication in 2000 of the European Water Framework Directive (WFD) and later in 2008 of the European Marine Framework Directive (MSFD), which settled one descriptor based on the food-web and one on the species. Several actions are worth to be mentioned here. Some were individual such as de Jonge et al. (2003, 2012, accepted B), de Jonge and Schückel (submitted to this SI) and de Jonge (2007) in connection to the WFD. Patrício et al. (2009) have helped advance the use of indicators (particularly benthic ones) applied to estuarine water quality. Also, Baird (2012; et al., 2001) promoted the use of ecological network indicators in studies of the Sylt-Rømø Bight. Regarding the MSFD again, groups of researchers gathered to coordinate answers to this demand and published the results in the context of EU collaborative projects (e.g., Lynam et al. 2016; Piroddi et al. 2015), or ICES groups (e.g., Tam et al., 2017), or OSPAR groups (e.g. Rombouts et al., 2013, Safi et al., submitted to this SI). One of the early coordinated efforts defined a list of indicators in ecosystem-based management using food web functioning of fishing activities (called EAF for Ecosystem Approach to Fisheries). From the end of the 2000s, members of this consortium set up large inter-ecosystem comparisons of marine exploited systems through the group IndiSeas, whose work recently led to the publication of numerous articles (e.g., Fu et al., 2018; Reed et al., 2016; Coll et al., 2016; Bundy et al., 2016). Among the different indicators considered, the ENA indices appeared as a new way of describing the flows in the entire system ("functional" and "holistic" indicators), even if more research was still considered as needed to make them operational.

Decision makers are looking for characteristic or SMART indicators (Doran, 1981) that at the same time are also quite specific and sound (ROARS; see e.g., www.mnestudies.com), are 'simple, cheap, easy to understand' (de Jonge et al., 2012), and thus, appealing for the shortterm, high pressure needs of the decision-maker (de Jonge et al., 2003). The specifications of the required indicators are presented in Box $\# 1$. Some further requirements for indicators are that they i) are limited in number, ii) comprise a mix of quantitative and qualitative indicators, iii) are practical \& simple (direct the problem and the solution), iv) are easily communicable, and v) inform human society about the situation. It is not possible to meet all these requirements in this paper, but a start will be made by confronting what we have available with the requirements set by the users. Based on the list of suggested indicators (Table 2), we attempt to test their suitability preliminarily against the 
Qualities of Good Indicators: ROARS

Relevant: It relates to an important part of an objective or output

Objective: Based on facts, rather than feelings or impressions and thus measurable

Available: Data should be readily available or reasonably measurable

Realistic: It should not be too difficult or too expensive to collect the information

Specific: The measured changes should be expressed in precise terms

Characteristics of Good indicators are also SMART:

Specific: Measured changes should be expressed in precise terms and suggest the direction of actions

Measurable: Indicators should be related to things that can be measured in an unambiguous way

Achievable: Indicators should be reasonable and possible to reach, and therefore sensitive to changes

Replicable: Measurements should be the same when made by different people using the same method

Time-bound: There should be a time limit within which changes are expected and measured

Table 3

Assessment of indicators for aspects critical to management and communication with managers. Table values generated from expert input of the paper authors.

\begin{tabular}{|c|c|c|c|c|c|c|c|}
\hline Indicator & 1) APL & 2) FCI & 3) MTL & 4) $\mathrm{D} / \mathrm{H}$ & 5) Keystone & 6) SI & 7) $\Phi / \mathrm{DC} \mathrm{A} / \mathrm{DC}$ \\
\hline Relevant & ++ & ++ & + & + & - & + & ++ \\
\hline Objective & ++ & ++ & + & + & + & ++ & ++ \\
\hline Available & + & $-/+$ & + & + & + & - & $+1-$ \\
\hline Realistic & + & - & - & + & - & + & + \\
\hline Specific $^{2}$ & + & - & - & + & $+/-$ & $+1-$ & + \\
\hline Measurable & + & + & + & + & + & $+1-$ & + \\
\hline Achievable & + & + & + & + & $+1-$ & + & + \\
\hline Replicable & + & + & + & ++ & + & + & ++ \\
\hline Communicable $^{3}$ & ++ & + & + & ++ & ++ & $+1-$ & + \\
\hline
\end{tabular}

presented requirements in Box \#1. All of the indicators presented are important, but they are at the moment not easily understandable to non-experts and thus also not all easily communicable (Table 3).

Most attractive of all Table 3 indices is the fact that they are replicable and not subjective, given that the basic data set is good (flow matrix and energetics table). However, all are affected by the degree of aggregation of the network and the flow balancing of the living and the non-living compartments.

\subsection{Average path length}

The APL index is for general purposes very useful. It basically indicates what part of the boundary input is not used by the ecosystem and calculates an index based on ratio of throughflow to boundary flow. The maximum of this value is reached when the boundary flow approaches zero and the APL approaches infinity $(\infty)$. This occurs when there is significant cycling such that a high internal flow is maintained for a small input. Thus, a high or increasing APL reflects a rather developed or developing system. The index is thus dependent on good estimates of ecosystem boundary input values. One weakness, similar to any of the flow-based methods, is that if the study cannot provide accurate enough values for external carbon inputs then users should be careful in using the index. A second weak point for decision makers is that there is no generic optimum value or minimum value available, but that their magnitudes are system specific.

\subsection{Finn Cycling Index}

The recycling is a property of ecosystem functioning which is central in trophic ecology studies. The recycling is associated with the ability of a system to re-use material and avoid loss, leading to a better efficiency. It has also been associated with a buffer reaction to human induced system stress, with recycling leading to a greater resistance (Saint-Béat et al., 2015). Observations are numerous of observed effects of pressures on the ecosystem leading to higher recycling. The concept was already proposed in Odum (1985), and was then quantified in numerous applications of the FCI calculation in inter-system comparisons with differences of pressures. Recently, de Jonge et al. (accepted A) demonstrated a strong increase of FCI in an estuary in upstream direction where the concentrations of non-living carbon and turbidity naturally increased. Tecchio et al. (2015) observed a higher FCI after the building of the Port 2000 extension of the harbor of Le Havre, in the Seine estuary. Higher FCI corresponds to higher re-use, but as stated above this may also occur when the system is stressed so it is necessary to know the context of the system which produces the FCI value. A disadvantage of the indicator is that also here there is no clear reference value.

\subsection{Mean trophic level}

The MTL describes how the consumers organize in shorter or longer chains (Shannon et al. 2014; Coll et al., 2016). This is a simple and intuitive metric that gives an overall impression of the complexity of the food web. A system with a higher MTL implies a more complex ecosystem. While the index does not have any immediate management implication on its own, it could be used for long term monitoring to indicate if there is a harmful disturbance in the system, which would result in a decreasing MTL of the catch (MTLC). The "Fishing down the food web" paradigm (Pauly et al., 1998) is based on the assumption that increasing fishing pressure leads to a continuous reduction in MTLC since the high TL species are removed first. While this reduction in MTLC has been observed in many fisheries, the mechanism behind the observed decrease in MTLC may differ between systems.

Often fishermen increasingly target the low trophic level species because of their higher overall productivity, which also results in a decrease in MTLC but does not necessarily mean overfishing of the high TL species (Sethi et al., 2010; Rehren et al., 2018; Tuda et al., 2016). Branch et al. (2010) show that the negative trend in global MTLC observed at the end of the 1990s is no longer supported by the most recent decades of data. Looking at the Swedish fishery, Hornborg et al. (2012) also show that there was no correlation between landings and survey data MTL and conclude that the trend in landing MTL appears to be, at 
most, a weak measure of the ecosystem state and pressures on biodiversity in the area. Shannon et al. (2014) further evaluated a number of trophic level indicators, including MTL, and conclude that they can be useful, especially when a trophic level threshold (excluding lower trophic levels) is used. We may conclude from the above that the use of MTLC as an indicator of the state of an ecosystem can be meaningful if additional information is available on the relative contribution of the different species to the MTL.

\section{4. $D / H$ ratio}

This ratio, indicating the importance of detritus compared to that of primary production products is very appealing because it can easily be explained to non-experts. However, the index should preferably be used in complement to other information to provide the required detail of interpretation. For example, the average path length will give valuable information on the residence time of the matter within the food-web, but it will not describe if this matter comes directly from primary producers or from detritus, produced locally (local recycling) or imported (allochthonous recycling). This is why several articles describing food web functioning in different situations have joined these indices together (e.g., Horn et al., 2017, de la Vega et al., in press). In their article comparing three tidal ecosystems of the Wadden Sea, de la Vega et al. (in press) showed that main features of system functioning such as the $\mathrm{D} / \mathrm{H}$ ratio are influenced by the dominant habitat type of the studied area. Specifically, de la Vega observed that the Jade Bay system, dominated by mudflats relied on detritivory pathways (D/H ratio 2.44 ) whereas the Sylt-Rømø Bight and the Norderaue tidal basin are dominated by herbivory pathways (D/H ration 0.9 and 0.87 , respectively) attributed due to high standing stocks of suspension feeding mussel beds. However, within any existing ecosystem, the typical flow configuration is a web, rather than a chain. An increase in the $\mathrm{D} / \mathrm{H}$ ratio of an ecosystem between two points in time is to be interpreted as a relative change between that of natural variability and that caused by extreme events including human intervention. If primary productivity is low, then it also indicates that the system can sustain its activity (throughflow) only by increasing detritivory, which in turn will increase the internal cycling of material (and therefore the FCI). This also has implications for the detritivory as a buffering capacity as indicated by de Jonge and Schückel (submitted to OCMA for this SI). If the main detritus producers are plants or algae, then the extent of detritivory will decrease with a decrease in primary productivity. It is therefore important to have good knowledge of the flow structure between individual nodes for the interpretation of network indices.

\subsection{Keystoneness}

This index represents the overlap of trophic interactions and indicates a mutual influence between species. It falls in the category 'easy to understand and to communicate to decision makers'. Sensitivity analysis regarding this parameter is an ongoing area of research. The index, however, has potential when it comes to exploring effects of specific management or conservation measures where the composition of species and their key role capacities come into play. Some prominent examples for ecosystem changes due to man-made removal/addition of keystone species have been reported from terrestrial and marine systems. These are the extinction of wolves in Yellowstone Park in 1920 and its reintroduction as a management measure in 1995 (i.e. Berger et al., 2008; Berger and Smith, 2005), and the extirpation of sea-otters at the American west coast from 1741 until 1910, its influence on the kelp beds and its recovery due to protection measures in 1911 (Estes and Palmisano, 1974; Kenyon, 1969). In both cases the consequences of the recovery of the keystone species on the total ecosystem could have been predicted by using the proposed index and combining it with an ENA-impact analysis.

Jordán (2009) describes three options to understand networks and their central players better. Aggregation of the network does not facilitate to find a keystone species because the bias of the biological content is potentially large. The focus on an isolated subgraph of the network leads to problems explaining how the neglected external effects are influencing members of the subsystem. Another method is to consider the heterogeneity of the network, to determine critical nodes and deriving indices from it. Considering the number of neighbors leads to define the degree (D) as the number of neighbors of a graph node to define the positional importance or the "topological importance". Some keystone species such as the Asteroid Pisaster ochraceus (Paine, 1969) has only few direct partners but a rich indirect interaction system. Therefore, also the neighbors of these neighbors must be included in the assessment of keystoneness.

Biologists are often faced to document a cascade effect in a food web after a species is removed by local extirpation or extinction. Decisions on measures about the re-colonization process of wolves in Europe as well as the conflict between fishermen and seals in the Wadden Sea or other coastal areas could be facilitated by using this special index combined with ENA models.

\subsection{Structural Information}

This index provides information complimentary to that of other entropy-based indicators. However, it also clearly adds a challenge for decision makers to fully understand them, in that the information provided is less easily interpretable than that of the structural indicators discussed so far. Structural Information provides an interpretation of the system's organization from the biomass distribution between smaller $\mathrm{r}$ - and larger K-strategists, and insofar is a valuable contribution to understanding of its structure.

In the context of Ecological Network Analysis, SI can be of particular interest, as it provides a complimentary information to that provided by other entropy-based indicators typically used to measure the information embedded in the flow structure of a network, i.e. Average Mutual Information (AMI) and Flow Diversity (H). Altogether, these indicators can give a comprehensive picture of an ecological network, describing the information embedded in network composition (SI), network connectivity and equitability (H) and network determinacy (AMI). Moreover, it has been shown (Ludovisi and Scharler, 2017) that their responses along a putative successional pathway give rise to a pattern that conceptually agrees with the current ecosystem theory. Since these indices share the common currency of entropy/information, they lend themselves to be combined in order to obtain a comprehensive indicator of network complexity. As shown by Scharler and Ludovisi (Sylt ENA workshop, 2017), a particular combination of these indicators can represent a promising orientor of network development, and thus a potential suitable indicator of ecosystem's health state.

The main focus of ecological state assessment is to reach a single, objective as possible and comprehensive figure able to express the condition of an entire ecosystem. The current standard protocols based on the bioindication concept use the abundance data of organisms belonging to various ecological categories (macrophytes, fish, macrobenthos, diatoms, etc.) to give partial judgements of ecosystem state. The partial judgements are then often weighted and averaged in order to reach a unique index representative of ecosystem state. Such a procedure entails several practical drawbacks for any single category, mostly dealing with the incomplete knowledge of ecological optimum/ tolerance by species, uncertainty in taxonomic attribution, problems in extending bioindicator values to different biogeographical area. And, what if the partial judgments obtained for different ecological categories are very different from one another? Is it ecologically proper to average the response of different ecological categories as if they were independent of one another?

Moreover, and more conceptually, is a judgement based on species tolerance of certain conditions a true indicator of ecological quality? In this respect, indicators reflecting the distance covered by an ecosystem 
away from the 'dead state' (i.e. a state without life), such as SI, could represent useful and practical tools to reach a reliable assessment of ecosystem state and quality. A case study showing the potential effectiveness of SI as a tool for ecosystem state assessment is reported in Ludovisi (2014). The author calculated SI for three Byelorussian lakes, which are adjacent, connected to each other and have similar morphology, hydrology and hydro-chemical features, but very different trophic state and biocoenosis. The results showed that SI, calculated on the basis of the whole biocoenosis (from algae to fish and macrophytes), increased clearly from the hypereutrophic Lake Batorin to the mesotrophic Lake Myastro and to the oligotrophic Lake Naroch, reflecting the marked changes in the dominance of the various ecological categories. From a theoretical point of view, such results confirms the thought of Odum (1969a,b) that eutrophication pushes an ecosystem back, in successional terms, to a younger or 'bloom' state". From a more practical standpoint, SI gives a measure of how much an ecosystem has moved along the successional path, and thus represents one of the most 'objective' measures of ecological state and quality.

\subsection{Information based indicators}

This category consists of several indices such as the flow diversity $(\mathrm{H})$, the ascendency (A), the overhead or loss of information in redundant pathways $(\Phi)$, the development capacity (DC), the average mutual information (AMI), or the internal redundancy of the flows (R). Assessing the system functioning and structure (e.g., by the relative overhead, flow diversity $\mathrm{H}$, or robustness) is something the $\mathrm{EU}$ Commission appreciates (EC, 2000, 2008). Apart from the flow diversity also the relative ascendency (A/DC and which is also related to the Robustness) and relative overhead ( $\Phi / D C)$ are very interesting for decision making because they indicate the efficiency (A/DC) and the overall resilience $(\Phi / D C)$ of ecosystems. The latter two indices are even more interesting since they scale between 0 and 1 because $1=\mathrm{A}$ / DC $+\Phi / D C$. This definite scale is something decision makers appreciate because it facilitates interpretation. Further, there are indications that the relative overhead $(\Phi / D C)$ can be related to the species diversity (de Jonge and Schückel in prep). Due to the work on the Robustness indicator we know that $\Phi / D C$ has an optimum $(0.61$, the highest point on the robustness curve) (Ulanowicz et al., 2009). The robustness indicator has the advantage of a known optimum value, which facilitates studies related to the effects of system stress as well as foreseen measures to diminish it and makes it very attractive one for decision makers. Redundancy represents only part of the $\Phi / D C$ but indicates the system's potential flexibility to respond to perturbations (Heymans et al., 2014; Heymans and Tomczak, 2016; Tomczak et al., 2013). Both $\Phi / D C$ and $A / D C$ seem thus very suitable as an overall characterization of the resilience of any ecosystem. Taken into the robustness metric, an optimum value is apparent, and a region where viable ecosystems exist (Ulanowicz et al., 2009).

Numerous studied have been led recently in order to test the hypothesis that such indices may be sensitive to different sources of stress. In the case of the Seine Estuary, where the pressure is forming a gradient from North (high pressure, close the harbor of Le Havre) to South (low pressure, protected area), the system showed in the same direction a rising activity (TSTflow) associated with a rising diversity of flows $(\mathrm{H})$ (Tecchio et al., 2015). In neighboring Bay of Seine, the simulation of the reef effect, associated with the future building of offshore wind farms, was shown to increase the total activity of the system but to decrease the relative ascendency (A/DC) showing a less mature system associated to this new hard substrate appearance in the middle of a soft bottom habitat (Raoux et al., 2018). Tam et al. (2017) evaluated MTL, FCI, and information based indicators within a long list of proposed indicators and received good marks in "availability" and "conceptual" items but low rates in "communication" and "management". Lynam et al. (2016) reviewed available modelling methods applied to ecosystems and discussed ENA in the context of simulation of climate change effects on the distribution of species. For example, the Bay of Biscay ecosystem was studied to investigate the effect of climate change on the distribution of small pelagic fish and its consequences on food web functioning (Chaalali et al., 2016). There is also a growing literature to apply this information based approach to economic studies (Kharrazi et al. 2013, 2017; Goerner et al., 2015).

\subsection{Future directions}

While we intend that this paper provide useful overview and guidance to practitioners of ecosystem management, we recognize that application and implementation of these tools and metrics is still progressing. There are several challenges that remain to be addressed to improve the use and communication of the metrics. From a scientific perspective, future work should focus on further developing the underlying theory behind the indicators to better understand the causative factors that influence the values. This should only help our ability to implement and communicate the metrics. Second, there is also the question of model and empirical data sensitivity. This gets to the question of conceptualizing the system, setting the system boundary, and selecting the nodes to be included. For example, it is known that model aggregation (lower diversity of species represented in the model) can affect the metric values (Fath et al., 2013; Baird et al., 2009, Allesina et al., 2005; Abarca-Arenas and Ulanowicz, 2002; de Jonge et al. accepted), and uncertainty in model parameterization (e.g., flow estimations) can also impact ENA results (Kones et al., 2009; Kaufman and Borrett, 2010; Hines et al., 2018; Waspe et al., 2018). Heymans et al. (2014) demonstrate the difficulties that arise from modeler bias resulting in model topology when comparing across ecosystems. While there is yet no settled theory of modelling about how to construct the model, some guidance is provided in Fath et al. (2007).

A few studies (Heymans et al., 2007; Heymans and Tomczak, 2016; Tomczak et al., 2013) have used network metrics to detect change of ecosystem state in terms of flipping from one regime to another. However, this is an area of open research as thresholds for regime shifts are difficult to discern. For example, is it possible to say that an $\mathrm{FCI}=0.25$ is healthy, yet, 0.24 is not? We are doubtful that this is the case given the "grey zone" in both the ecosystems and the indicators used to assess them and would warn against spending too much time looking for generic thresholds. A more fruitful approach is to use them for comparative analyses across time and space. Benchmarks of healthy and unhealthy ecosystems could be used as well as observations of dynamic trends the ecosystem undergoes Lau et al., (2017).

Lastly, we advise decision makers not to seek one magic bullet. Ecosystems are not only complex but also at the same time adaptive (Levin et al., 1998). It is only sensible that it would take multiple dimensions and methods to evaluate and interpret the high number of interactions and feedbacks. Therefore, it should be recognized that not one indicator addresses all the concerns, but rather that they are complementary and should be used as a toolbox of approaches. The advantage is that all are calculated from the same food web monitoring and datasets, such that once one has the data needed to calculate one the others will follow. Data needed for calculation can be collected according to current protocols used for the assessment of the ecological status of water bodies or habitats. For example, in the North Sea region, existing monitoring programs imposed by MSFD and other EU Directives, such as the Habitats Directive (92/43/EEC), the Birds Directive (2009/147/EC) and the Water Framework Directive (WFD, Directive 2000/60/EC) or the Trilateral Monitoring Assessment Program in the Wadden Sea (TMAP) are compatible with requirements to build up a network. ENA software exists (Fath and Borrett, 2006; Borrett and Lau, 2014) to make these calculations all in one software package. Therefore, a critical piece for success is continuous ecosystem-scale monitoring necessary to implement the Ecological Network Analysis metrics described herein, and the successful translation of scientific results to the management and policy realm. 


\section{Conclusions}

There is a movement in the policy community to address the functional aspects of ecosystems using holistic frameworks such as the Water Framework Directive (WFD, Directive 2000/60/EC), the Marine Strategy Framework Directive (MSFD), the Sustainable Development Goals (SDGs), and numerous other approaches from around the world. The present paper contributes to the ongoing requirements in politics and management to assess and manage marine ecosystems in a holistic way specifically using food web indicators and a holistic ecosystems approach (Tam et al., 2017).

The short list of indicators provided here contains some indicators that can be applied more or less immediately as a first step to create a foundation for EBM by an unambiguous ecosystem assessment as demanded by the European Union (e.g. EC, 2000, 2008). These indicators are $\Phi / \mathrm{DC}, \mathrm{A} / \mathrm{DC}, \mathrm{D} / \mathrm{H}, \mathrm{H}, \mathrm{APL}, \mathrm{MTL}$, and FCI because these can easily be communicated with decision makers. Because the other indicators presented here are more complex and/or more theoretical, they are seen as foundational for additional indices in future assessments.

The metrics described here are not a complete not a definite list of the ecological network metrics, but they were singled out by experts at the workshop as metrics that have been widely applied and have the greatest potential to convey meaningful and understandable information to stakeholders and decision-makers. These metrics have been used in numerous studies as described above and we have confidence that they provide useful and trustworthy information and insight for better ecosystem management. We anticipate that with further application and discussion of additional network metrics more will be incorporated in environmental management. This can only be ascertained following more use of the approaches, which we greatly encourage.

\section{Acknowledgement}

Ulrike Schückel was supported by the joint research project STopPSynthese (FKZ03F0745A) funded by the German Federal Ministry of Education and Research (BMBF).

\section{Appendix A. Supplementary data}

Supplementary data to this article can be found online at https:// doi.org/10.1016/j.ocecoaman.2019.03.007.

\section{References}

Abarca-Arenas, L.G., Ulanowicz, R.E., 2002. The effects of taxonomic aggregation on network analysis. Ecol. Model. 149, 285-296.

Acosta, L.A., Wintle, B.A., et al., 2016. Using Scenarios and Models to Inform Decision Making in Policy Design and Implementation. IPBES, pp. 37-80 2016: Methodological assessment of scenarios and models of biodiversity and ecosystem services. S. Ferrier, K. N. Ninan, P. Leadleyet al. Bonn, Germany, Secretariat of the Intergovernmental Platform for Biodiversity and Ecosystem Services.

Allesina, S., Bondavalli, C., Scharler, U.M., 2005. The consequences of the aggregation of detritus pools in ecological networks. Ecol. Model. 189, 221-232.

Araújo, M.B., Rozenfeld, A., Rahbek, C., Marquet, P.A., 2011. Using species co-occurence networks to assess the impacts of climate change. Ecography 34, 897-908.

Baird, D., 2012. Assessment of observed and perceived changes in ecosystems over time, with special reference to the Sylt-Rømø Bight, German Wadden Sea. Estuar. Coastal Shelf Sci. 108, 144-154.

Baird, D., Ulanowicz, R.E., 1993. Comparative study on the trophic structure, cycling and ecosystem properties of four tidal estuaries. Mar. Ecol. Prog. Ser. 221-237.

Baird, D., Asmus, H., Asmus, R., 2007. Trophic dynamics of eight intertidal communities of the Sylt-Rømø Bight ecosystem, northern Wadden Sea. Mar. Ecol. Prog. Ser. 351, $25-41$.

Baird, D., Fath, B.D., Ulanowicz, R.E., Asmus, H., Asmus, R., 2009. On the consequences of aggregation and balancing of networks on system properties derived from ecological network analysis. Ecol. Model. 220, 3465-3471.

Berger, J., Smith, D.W., 2005. Restoring functionality in Yellowstone with recovering carnivores: gains and uncertainties. In: Ray, J.C., Redford, K.H., Steneck, R.S., Berger, J. (Eds.), Large Carnivores and the Conservation of Biodiversity. Island Press, Washington, D.C, pp. 100-109.

Berger, K.M., Gese, E.M., Berger, J., 2008. Indirect effects and traditional trophic cascades: a test involving wolves, coyotes and pronghorn. Ecology 89 (3), 818-828.
Biodiversity Indicators Partnership, 2010. Biodiversity Indicators and the 2010 Target: Experiences and Lessons Learnt from the 2010 Biodiversity Indicators Partnership. Secretariat of the Convention on Biological Diversity, Montreal, Canada, pp. 196 Technical Series no. 53.

Bond, W., 2001. Keystone species - hunting the shark? Science 292, 63-64.

Bondavalli, C., Ulanowicz, R.E., 1999. Unexpected effects of predators upon their prey: the case of the American Alligator. Ecosystems 2, 49-63.

Borrett, S.R., 2013. Throughflow centrality is a global indicator of the functional importance of species in ecosystems. Ecol. Indicat. 32, 182-196.

Borrett, S.R., Lau, M.K., 2014. enaR: an r package for ecosystem network analysis. Methods Ecol. Evol. 5, 1206-1213.

Borrett, S.R., Sheble, L., Moody, J., Anway, E., 2018. Bibliometric review of ecological network analysis: 2010-2016. Ecol. Model. 382, 63-82.

Branch, T.A., Watson, R., Fulton, E.A., Jennings, S., McGilliard, C.R., Pablico, G.T., Ricard, D., Tracey, S.R., 2010. The trophic fingerprint of marine fisheries. Nature 468, 431-435.

Bundy, A., et al., 2016. Strong fisheries management and governance positively impact ecosystem status. Fish Fish. 18 (3), 412-439.

Chaalali, A., Beaugrand, G., Raybaud, V., Lassalle, G., Saint-Béat, B., Le Loc'h, F., Bopp, L. Tecchio, S., Safi, G., Chifflet, M., Lobry, J., Niquil, N., 2016. From species distributions to ecosystem structure and function: a methodological perspective. Ecol. Model. 334, 78-90.

Christensen, V., Pauly, D., 1992. ECOPATH II - a software for balancing steady-state ecosystem models and calculating network characteristics. Ecol. Model. 61, 169-185.

Coll, M., Shannon, L.J., Kleisner, K.M., Juan-Jordá, M.J., Bundy, A., Akoglu, A.G., Banaru, D., Boldt, J.L., Borges, M.F., Cook, A., Diallo, I., 2016. Ecological indicators to capture the effects of fishing on biodiversity and conservation status of marine ecosystems. Ecol. Indicat. 60, 947-962.

Cazzolla Gatti, R., Fath, B., Hordijk, W., Kauffman, S., Ulanowicz, R., 2018. Niche emergence as an autocatalytic process in the evolution of ecosystems. J. Theor. Biol. 454, 110-117.

Christian, R.R., Baird, D., Luczkovich, J., Johnson, J.C., Scharler, U.M., Ulanowicz, R.E., 2005. Role of network analysis in comparative ecosystem ecology of estuaries. In: Belgrano, A., Scharler, U.M., Dunne, J., Ulanowicz, R.E. (Eds.), Aquatic Food Webs. Oxford University Press, Oxford, pp. 25-40.

Christensen, V., 1995. Ecosystem maturity-towards quantification. Ecol. Model. 77 (1), $3-32$.

Chrystal, R.A., Scharler, U.M., 2014. Network analysis indices reflect extreme hydrodynamic conditions in a shallow estuarine lake (Lake St Lucia), South Africa. Ecol. Indicat. 38, 130-140.

Dale, V.H., Beyeler, S.C., 2001. Challenges in the development and use of ecological indicators. Ecol. Indicat. 1, 3-10.

de Jonge, V.N., 1995. Wind driven tidal and annual gross transport of mud and microphytobenthos in the Ems estuary, and its importance for the ecosystem. In: Dyer, K.R., Orth, R.J. (Eds.), Changes in Fluxes in Estuaries, pp. 29-40 Olsen \& Olsen, Fredensborg, Denmark 05.03 V.N. de Jonge, 1995. The Ems Estuary. A case study, 81-107. In: A.J.McComb (ed.) Eutrophic Shallow Estuaries and Lagoons, CRC-Series, CRC Press. 240 pp.

de Jonge, V.N., 2007. Toward the application of ecological concepts in EU coastal water management. Mar. Pollut. Bull. 55, 407-414.

de Jonge, V.N., van Beusekom, J.E.E., 1995. Wind and tide induced resuspension of sediment and microphytobenthos from tidal flats in the Ems estuary. Limnol. Oceanogr. 40, 766-778.

de Jonge, V.N., Kolkman, M.J., Ruijgrok, E.C.M., de Vries, M.B., 2003. The need for new paradigms in integrated socio-economic and ecological coastal policy making. In: Proceedings of 10th International Wadden Sea Symposium, (2003). Ministry of Agriculture, Nature Management and Fisheries, Department North, Groningen, pp. 247-270 $272 \mathrm{pp}$.

de Jonge, V.N., Pinto, R., Turner, R.K., 2012. Integrating ecological, economic and social aspects to generate useful management information under the EU Directives' 'ecosystem approach'. Ocean Coast Manag. 68, 169-188.

de Jonge, V.N., Schückel, U., Baird, D., 2018. Effects of spatial scale, species aggregation and balancing on carbon flows and ecological network analysis indicators of food webs. Mar. Ecol. Prog. Ser (accepted A). https://doi.org/10.3354/meps12825.

de Jonge, V.N., Schückel, U., Baird, D., 2019. Subsets of food webs cannot be used as a substitute to assess the functioning of entire ecosystems. Mar. Ecol. Prog. Ser (accepted B).

de Jonge, V.N., Schückel, U. (submitted this SI). Exploring the effects of dredging and organic waste on the quantitative structure and functioning of three regional estuarine food webs by Ecological Network Analysis. Ocean Coast Manag.

Doran, G.T., 1981. There's a S.M.A.R.T. way to write management's goals and objectives. Manag. Rev. AMA FORUM 70 (11), 35-36.

EC, 2000. Directive 2000/60/EC of European Parliament and of the Council of 23 October 2000 establishing a framework for community action in the field of water policy. Offic. J. Eur. Commun. L 327, 1-73.

EC, 2008. Directive 2008/56/EC of the European parliament and of the council of 17 June 2008 establishing a framework for community action in the field of marine environmental policy (marine strategy framework directive). Offic. J. Eur. Commun. L 164, 19-40.

Estes, J.A., Palmisano, J.F., 1974. Sea otters: their role in structuring nearshore communities. Science 185 (4156), 1058-1060.

Essington, T.E., Beaudreau, A.H., Wiedenmann, J., 2006. Fishing through marine food webs. Proc. Natl. Acad. Sci. U. S. A. 103, 3171-3175.

Estes, J.A., Tinker, M.T., Williams, T.M., Doak, D.F., 1998. Killer whale predation on sea otters linking oceanic and nearshore ecosystems. Science 282, 473-476.

Fath, B.D., Patten, B.C., 1999. Review of the foundations of network environ analysis. 
Ecosystems 2, 167-179.

Fath, B.D., Borrett, S.R., 2006. A Matlab ${ }^{\circledR}$ function for network environ analysis. Environ. Model. Softw. 21, 375-405.

Fath, B.D., Jørgensen, S.E., Patten, B.C., Straskraba, M., 2004. Ecosystem growth and development. Biosystems 77, 213-228.

Fath, B.D., Scharler, U., Ulanowicz, R.E., Hannon, B., 2007. Ecological network analysis: network construction. Ecol. Model. 208, 49-55.

Fath, B.D., Scharler, U.M., Baird, D., 2013. Dependence of network metrics on model aggregation and throughflow calculations: demonstration using the Sylt-Rømø Bight Ecosystem. Ecol. Model. 252, 214-219.

Finn, J.T., 1976. Measures of ecosystem structure and function derived from analysis of flows. J. Theor. Biol. 56, 363-380.

Finn, J.T., 1980. Flow analysis of models of the Hubbard Brook ecosystem. Ecology 61, $562-571$.

Fu, C., Travers-Trolet, M., Velez, L., Grüss, A., Bundy, A., Shannon, L.J., Fulton, E.A., Akoglu, E., Houle, J.E., Coll, M., Verley, P., Heymans, J.J., John, E., Shin, Y.-J., 2018. Risky business: the combined effects of fishing and changes in primary productivity on fish communities. Ecol. Model. 368, 265-276.

Goerner, S., Fiscus, D.A., Fath, B.D., 2015. Using Energy Network Science (ENS) to connect resilience with the larger story of systemic health and development. Emerg. Complex. Org. 17, 3.

Grasshoff, K., Erhardt, M., Kremling, K., 1983. Methods of Seawater Analysis. Verlag Chemie, Weinheim.

Hannon, B., 1973. The structure of ecosystems. J. Theor. Biol. 41, 535-546.

Helsenfeld, P., Enserink, E.L., 2008. OSPAR ecological quality objectives: the utility of health indicators in the North Sea. ICES J. Mar. Sci. 65, 1392-1397.

Heymans, J.J., Coll, M., Libralato, S., Morissette, L., Christensen, V., 2014. Global patterns in ecological indicators of marine food webs: a modelling approach. PLoS One 9 (4), e95845.

Heymans, J.J., Guénette, S., Christensen, V., 2007. Evaluating network analysis indicators of ecosystem status in the Gulf of Alaska. Ecosystems 10, 488-502.

Heymans, J.J., Ulanowicz, R.E., Bondavalli, C., 2002. Network analysis of the South Florida Everglades graminoid marshes and comparison with nearby cypress ecosystems. Ecol. Model. 149 (1-2), 5-23.

Heymans, J.J., Coll, M., Link, J.S., Mackinson, S., Steenbeek, J., Walters, C., Christensen, V., 2016. Best practice in Ecopath with Ecosim food-web models for ecosystem-based management. Ecol. Model. 331, 173-184.

Heymans, J.J., Tomczak, M.T., 2016. Regime shifts in the Northern Benguela ecosystem: challenges for management. Ecol. Model. 331, 151-159.

Hines, D.E., Ray, S., Borrett, S.R., 2018. Uncertainty analyses for ecological network analysis enable stronger inferences. Environ. Model. Softw. 101, 117-127.

Hornborg, S., Nilsson, P., Valentinsson, D., Friederike, Z., 2012. Integrated environmental assessment of fisheries management: Swedish Nephrops trawl fisheries evaluated using a life cycle approach. Mar. Policy 36 (6), 1193-1201.

Horn, S., de la Vega, C., Asmus, R., Schwemmer, P., Enners, L., Garthe, S., Binder, K., Asmus, H., 2017. Interaction between birds and macrofauna within food webs of six intertidal habitats of the Wadden Sea. PLoS One 12 (5), e0176381.

Jones, C.G., Lawton, J.H., Shachak, M., 1994. Organisms as ecosystem engineers. Oikos 69, 373-386.

Jordán, F., 2009. Keystone species and food webs. Phil. Trans. R. Soc. B364, 1733-1741.

Jørgensen, S.E., Patten, B.C., Straskraba, M., 2000. Ecosystems emerging: 4 growth. Ecol. Model. 126, 249-284.

Jørgensen, S., Ludovisi, A., Nielsen, S., 2010. The free energy and information embodied in the amino acid chains of organisms. Ecol. Model. 221, 2388-2392.

Jørgensen, S.E., Fath, B.D., Bastianoni, S., Marques, J.C., Müller, F., Nielsen, S.N., Patten, B.C., Tiezzi, E., Ulanowicz, R.E., 2007. A New Ecology - Systems Perspective. Elsevier, Amsterdam, pp. 275.

Kaufman, A.G., Borrett, S.R., 2010. Ecosystem network analysis indicators are generally robust to parameter uncertainty in a phosphorus model of Lake Sidney Lanier, USA. Ecol. Model. 221 (8), 1230-1238.

Kazanci, C., Ma, Q., 2015. Chapter 3 - system-wide measures in ecological network analysis. In: Park, Y.-S., Lek, S, Baehr, C., Jorgensen, S.E. (Eds.), Advanced Modelling Techniques Studying Global Changes in Environmental Sciences. Elsevier, pp. 45-68.

Kenyon, K.W., 1969. the sea otter in the Eastern Pacific ocean. N. Am. Fauna 68, 1-352.

Kharrazi, A., Rovenskaya, E., Fath, B.D., Yarime, M., Kraines, S., 2013. Quantifying the sustainability of economic resource networks: an ecological information-based approach. Ecol. Econ. 90, 177-186.

Kharrazi, A., Rovenskaya, E., Fath, B.D., 2017. Network structure impacts global commodity trade growth and resilience. PLoS One 190, 243-251.

Kones, J.K., Soetaert, K., van Oevelen, D., Owino, J.O., 2009. Are network indices robust indicators of food web functioning? A Monte Carlo approach. Ecol. Model. 220, 370-382.

Konar, B., 2000. Limited effects of a keystone species on community structure: long term trends at the Semichi Islands, Alaska. Mar. Ecol. Prog. Ser. 199, 271-280.

Lau, M.K., Borrett, S.R., Baiser, B., Gotelli, N.J., Ellison, A.M., 2017. Ecological network metrics: opportunities for synthesis. Ecosphere 8 (8).

Layke, C., Mapendembe, A., Brown, C., Walpole, M., Winn, J., 2012. Indicators from the global and sub-global Millennium Ecosystem Assessments: an analysis and next steps. Ecol. Indicat. 17, 77-87.

Levin, S.A., 1998. Ecosystems and the biosphere as complex adaptive systems. Ecosystems $1,431-436$.

Libralato, S., Christensen, V., Pauly, D., 2005. A method of identifying keystone species in food web models. Ecol. Model. 195, 153-171.

Lindeman, R.L., 1942. The trophic-dynamic aspect of ecology. Ecology 23 (4), 399-417.

Ludovisi, A., 2009. Exergy vs information in ecological successions: interpreting community changes by a classical thermodynamic approach. Ecol. Model. 220,
1566-1577.

Ludovisi, A., 2014. Effectiveness of entropy-based functions in the analysis of ecosystem state and development. Ecol. Indicat. 36, 617-623.

Ludovisi, A., Jørgensen, S.E., 2009. Comparison of exergy found by a classical thermodynamic approach and by the use of the information stored in the genome. Ecol. Model. 220, 1897-1903.

Ludovisi, A., Roselli, R., Basset, A., 2012. Testing the effectiveness of exergy-based tools on a seasonal succession in a coastal lagoon by using a size distribution approach. Ecol. Model. 245, 125-135.

Ludovisi, A., Scharler, U.M., 2017. Towards a sounder interpretation of entropy-based indicators in ecological network analysis. Ecol. Indicat. 72, 726-737.

Lynam, C.P., Uusitalo, L., Patrício, J., Piroddi, C., Queirós, A.M., Teixeira, H., Rossberg, A.G., Sagarminaga, Y., Hyder, K., Niquil, N., Möllmann, C., Wilson, C., Chust, G., Galpasoro, I., Forster, R., Verissimo, H., Tedesco, L., Revilla, M., Neville, S., 2016. Uses of innovative modelling tools within the implementation of the marine strategy framework directive. Front. Mar. Sci. 3, 182.

MacArthur, R.H., 1955. Fluctuations of animal populations, and a measure of community stability. Ecology 36, 533-536.

Mejer, H., Jørgensen, S., 1979. A holistic approach to ecological modelling. Ecol. Model. 7, 169-189.

Menge, B.A., 1995. Indirect effects in marine rocky intertidal interaction webs: patterns and importance. Ecol. Monogr. 65, 21-74.

Millennium Ecosystem Assessment (Program), 2005. Ecosystems and Human Well-Being. Island Press, Washington, D.C.

Mills, L.S., Soule, M.E., Doak, D.F., 1993. The keystone-species concept in ecology and conservation. Bioscience 43, 219-224.

Morowitz, H.J., 1968. Energy Flow in Biology. Academic Press, New York.

Mukherjee, J., Scharler, U.M., Fath, B.D., Ray, S., 2015. Measuring sensitivity of robustness and network indices for an estuarine food web model under perturbations. Ecol. Model. 306, 160-173.

Nicolis, G., Prigogine, I., 1977. Self Organization in Non Equilibrium Systems. WileyInterscience, New York.

Niquil, N., Chaumillon, E., Johnson, G.A., Bertin, X., Grami, B., David, V., Bacher, C., Asmus, H., Baird, D., Asmus, R., 2012. The effect of physical drivers on ecosystem indices derived from ecological network analysis: comparison across estuarine ecosystems. Estuar. Coast. Shelf Sci. 108, 132-143.

Odum, E.P., 1969. The strategy of ecosystem development. Science 164, 262-270.

Odum, E.P., 1985. Trends expected in stressed ecosystems. Bioscience 35 (7), 419-422.

Paine, R.T., 1969. A note on trophic complexity and community stability. Am. Nat. 103, 91-93.

Paine, R.T., 1994. In: Kinne, O. (Ed.), Marine Rocky Shores and Community Ecology: an Experimentalist's Perspective. Ecology Institute, Oldendorf/Luhe, Germany, pp. 152.

Patrício, J., Neto, J.M., Teixeira, H., Salas, F., Marques, J.M., 2009. The robustness of ecological indicators to detect long-term changes in the macrobenthos of estuarine systems. Mar. Environ. Res. 68 (1), 25-36.

Patten, B.C., 1978. Systems approach to the concept of environment. Ohio J. Sci. 78, 206-222.

Patten, B.C., 1995. Network integration of ecological extremal principles: exergy, emergy, power, ascendency, and indirect effects. Ecol. Model. 79, 75-84.

Pauly, D., Christensen, V., Dalsgaard, J., Froese, R., Torres Jr., F., 1998. Fishing down marine food webs. Science 279, 860-863.

Piroddi, C., Teixeira, H., Lynam, C.P., Smith, C., Alvarez, M.C., Mazik, K., Andonegi, E., Churilova, T., Tedesco, L., Chifflet, M., Chust, G., Galparsoro, I., Garcia, A.C., Kamari, M., Kryvenko, O., Lassalle, G., Neville, S., Niquil, N., Papadopoulou, N., Rossberg, A.G., Suslin, V., Uyarra, M.C., 2015. Using ecological models to assess ecosystem status in support of the European Marine Strategy Framework Directive. Ecol. Indicat. 58, 175-191.

Postma, H., 1967. Sediment transport and sedimentation in the estuarine environment. In: Lauff, G.H. (Ed.), Estuaries. Am. Assoc. Adv. Sci, pp. 158-179.

Power, M.E., Tilman, D., Estes, J.A., Menge, B.A., Bond, W.J., Mills, L.S., Daily, G., Castilla, J.C., Lubchenco, J., Paine, R.T., 1996. Challenges in the quest for keystones. Bioscience 46 (8), 609-620.

Raoux, A., Lassalle, G., Pezy, J.P., Tecchio, S., Safi, G., Ernande, B., Mazé, C., Le Loc'h, F., Lequesne, J., Girardin, V., Dauvin, J.C., Niquil, N., 2018. Measuring sensitivity of two OSPAR indicators for a coastal food web model under offshore wind farm construction. Ecol. Indicat. 1-11.

Reed, J., Shannon, L., Velez, L., Akoglu, E., Bundy, A., Coll, M., Fu, C., Fulton, E.A., Grüss, A., Halouani, G., Heymans, J.J., Houle, J.E., John, E., Le Loc'h, F., Salihoglu, B., Verley, P., Shin, Y.-J., 2016. Ecosystem indicators - accounting for variability in species' trophic levels. ICES J. Mar. Sci. 74 (1), 158-169.

Rehren, J., Wolff, M., Jiddawi, N., 2018. Fisheries assessment of Chwaka Bay (Zanzibar) following a holistic approach. J. Appl. Ichthyol. 34, 117-128.

Rombouts, I., Beaugrand, G., Fizzala, X., Gaill, F., Greenstreet, S.P.R., Lamare, S., Loch, F. Le, McQuatters-Gollop, A., Mialet, B., Niquil, N., Percelay, J., Renaud, F., Rossberg, A.G., Feral, J.-.P., 2013. Food web indicators under the marine strategy framework directive: from complexity to simplicity? Ecol. Indicat. 29, 246-254.

Safi, G., Giebels, D., Arroya, N.L., Heymans, J.J., Preciado, I., Raoux, A., Schückel, U., Tecchio, S., de Jonge, V.N., Niquil, N. (submitted). Vitamine ENA: a Framework for the Development of Ecosystem-Based Indicators for Decision- Makers. OCMA Present Special Issue.

Saint-Béat, B., Baird, D., Asmus, H., Asmus, R., Bacher, C., Pacella, C.R., Johnson, G.A., David, V., Vézina, A.F., Niquil, N., 2015. Trophic networks: how do theories link ecosystem structure and functioning to stability properties? A review, Ecol. Indicat. $52,458-471$.

Scharler, U.M., Baird, D., 2005. A comparison of selected ecosystem attributes of three South African estuaries with different freshwater inflow regimes, using network 
analysis. J. Mar. Syst. 56 (3), 283-308.

Scharler, U.M., 2008. Systems ecology: ecological network analysis, ascendency. In: Jorgensen, S.E., Fath, B.D. (Eds.), Encyclopedia of Ecology. Elsevier.

Scharler, U.M., Fath, B.D., 2012. Core Network Compartments: relative importance of ecosystem players in moving energy through the system. In: R Seppelt, A.,A., Voinov Lange, S.D., Bankamp (Eds.), Proceedings of the 2012 International Congress on Environmental Modelling and Software (iEMSs): Managing Resources of a Limited Planet, Sixth Biennial Meeting, Leipzig, Germany. 978-88-9035-742-8, .

Schrödinger, E., 1944. What Is Life? Cambridge University Press, Cambridge.

Schückel, U., Kröncke, I., Baird, D., 2015. Linking long-term changes in trophic structure and function of an intertidal macrobenthic system to eutrophication and climate change using ecological network analysis. MEPS 536, 25-38.

Sethi, S.A., Branch, T.A., Watson, R., 2010. Fishery development patterns are driven by profit but not trophic level. Proc. Natl. Acad. Sci. U.S.A. 107 (27), 12163-12167.

Shannon, L., Coll, M., Bundy, A., Gascue, D., Heymans, J.J., Kleisner, J., Lynam, C.P., Piroddi, C., Tam, J., Travers-Trolet, M., Shin, Y., 2014. Trophic level-based indicators to track fishing impacts across marine ecosystems. Mar. Ecol. Progr. Ser. 512, 115-140.

Strickland, J.D.H., Parsons, T.R., 1972. A practical handbook of seawater analysis. Fish. Res. Bd 167.

Tam, J.C., et al., 2017. Towards ecosystem-based management: identifying operational food-web indicators for marine ecosystems. ICES J. Mar. Sci. 74 (7), 2040-2052.

Tecchio, S., Coll, M., Sardà, F., 2015. Structure, functioning, and cumulative stressors of Mediterranean deep-sea ecosystems. Prog. Oceanogr. 135, 156-167.

Tomczak, M.T., Heymans, J.J., Yletyinen, J., Niiranen, S., Otto, S.A., Blenckner, T., 2013. Ecological network indicators of ecosystem status and change in the Baltic Sea. PLoS One 8 (10), e75439.

Tuda, P.M., Wolff, M., Breckwoldt, A., 2016. Size structure and gear selectivity of target species in the multispecies multigear fishery of the Kenyan South Coast- Ocean and
Coastal Management. 130, 95-106.

Ulanowicz, R.E., 1983. Identifying the structure of cycling in ecosystems. Math. Biosci. 65, 219-237.

Ulanowicz, R.E., 1986. Growth and Development, Ecosystems Phenomenology. SpringerVerlag, New York.

Ulanowicz, R.E., 1997. Ecology, the Ascendent Perspective. Columbia University Press, New York.

Ulanowicz, R.E., Hannon, B.M., 1987. Life and the production of entropy. Proc. R. Soc. B Biol. Sci. 232, 181-192.

Ulanowicz, R.E., Norden, J.S., 1990. Symmetrical overhead in flow networks. Int. J. Syst. Sci. 21, 429-437.

Ulanowicz, R.E., Puccia, C.J., 1990. Mixed trophic impacts in ecosystems. Coenoses 5, $7-16$.

Ulanowicz, R.E., Kay, J., 1991. A package for the analysis of ecosystem flow networks. Environ. Softw 6, 131-142.

Ulanowicz, R.E., Goerner, S.J., Lietaer, B., Gomez, R., 2009. Quantifying sustainability: resilience, efficiency and the return of information theory. Ecol. Complex. 6, 27-36.

Valls, A., Coll, M., Christensen, V., 2015. Keystone species: toward an operational concept for marine biodiversity conservation. Ecol. Monogr. 85 (1), 29-47.

van Oudenhoven, A.P., Schröter, M., Drakou, E.G., Geijzendorffer, I.R., Jacobs, S., van Bodegom, P.M., Chazee, L., Czúcz, B., Grunewald, K., Lillebø, A.I., Mononen, L., 2018. Key criteria for developing ecosystem service indicators to inform decision making. Ecol. Indicat. 95, 417-426.

Vo, Q.T., Kuenzer, C., Vo, Q.M., Moder, F., Oppelt, N., 2012. Review of valuation methods for mangrove ecosystem services. Ecol. Indicat. 23, 431-446.

Waspe, C.T., Mahabir, R., Scharler, U.M., 2018. FlowCAr: Flow Network Construction and Assessment in R. Vignette. https://doi.org/10.5281/zenodo.1408672.

Wiegert, R.G., Owen, D.F., 1971. Trophic structure, available resources and population density in terrestrial vs. aquatic ecosystems. J. Theor. Biol. 30, 69-81. 